\title{
Three-Dimensional Printing of "Green” Fuels for Low-Cost Small Spacecraft Propulsion Systems
}

\author{
Stephen A. Whitmore团 \\ Utah State University, Logan, Utah 84322-4130 \\ DOI: $10.2514 / 1 . \mathrm{A} 33782$
}

\begin{abstract}
This paper details the advantages of employing modern additive manufacturing methods to fabricate hybrid rocket fuels for intrinsically safe and green small spacecraft propulsion systems. Using additive manufacturing overcomes multiple issues frequently associated with hybrid propulsion, including poor volumetric efficiency, system ignitability, and low fuel regression rates. When certain three-dimensionally printed thermoplastics are subjected to a high-voltage low-wattage charge, electrostatic arcing along the surface pyrolizes a small amount of material that, with the introduction of an oxidizer, "seeds" combustion and produces immediate and reliable ignition. Thermoplastic fuel grains can be printed with port shapes that enhance burn properties and increase volumetric efficiencies. Embedded helical fuel ports significantly increase regression rates. The presented test results from several prototype systems using gaseous oxygen and printed acrylonitrile butadiene styrene demonstrate the various advantages of additive manufacturing, including low-power ignition, regression rate enhancement, and system scalability. The test results from both ambient and vacuum tests of a $25 \mathrm{~N}$ flight-weight small spacecraft thruster are presented. Multiple burn tests allowed statistical characterization of ignition timing and burn-to-burn thrust, as well as total impulse consistency. The test results demonstrating specific impulse values exceeding $295 \mathrm{~s}$ are presented. When fully developed, this propulsion technology has the potential for "drop-in" replacement of many hydrazine-based propulsion applications.
\end{abstract}

\section{Nomenclature}

$A^{*} \quad=$ choked nozzle throat area, $\mathrm{cm}^{2}$

$a=$ fuel regression rate fit scale factor, $(\mathrm{cm} / \mathrm{s})$ $\left(\mathrm{g} / \mathrm{s} \cdot \mathrm{cm}^{2}\right)^{n}$

$C_{F} \quad=$ thrust coefficient

$D_{0} \quad=\quad$ initial fuel port diameter, $\mathrm{cm}$

$d=$ helix loop diameter, $\mathrm{cm}$

$G_{\text {ox }} \quad=$ oxidizer mass flux, $\mathrm{g} / \mathrm{s} \cdot \mathrm{m}^{2}$

$I_{\mathrm{sp}} \quad=$ specific impulse, $\mathrm{s}$

$L=$ fuel port length, $\mathrm{m}$

$\dot{m}_{\text {fuel }}=$ solid fuel grain mass flow rate, $\mathrm{kg} / \mathrm{s}$

$\dot{m}_{\mathrm{ox}}=$ oxidizer mass flow rate, $\mathrm{kg} / \mathrm{s}$

$\dot{m}_{\text {total }}$

$N$

$n$

$O / F$

$P$

$P_{R}$

$P_{0}$

$p_{\text {exit }}$

$R_{g}$

$r$

$r_{0}$

$\dot{r}$

$S$

$T_{0}$

$t$

$\gamma$

$\Delta M_{\text {fuel }}=$

$\eta^{*}=$

$\begin{array}{lll}\mu & = & \text { sample mean } \\ \rho_{\text {fuel }} & = & \text { fuel material density, } \mathrm{g} / \mathrm{cm}^{3} \\ \sigma & = & \text { sample standard deviation } \\ \tau_{\text {rise }} & = & \text { motor ignition time, } \mathrm{ms}\end{array}$

\section{Introduction}

AECENT study by the European Space Agency's (ESA's) European Space Research and Technology Center (ESTEC) has identified two essential design elements to achieving low-cost commercial space access and operations: 1) reduced production, operational, and transport costs due to lower propellant toxicity and explosion hazards, and 2) reduced costs due to an overall reduction in subsystems complexity and overall systems interface complexity [1].2]. The ESA/ESTEC study showed the potential for considerable operational cost savings by simplifying propellant shipping, storage, and ground-handling procedures. Developing a nontoxic, stable green alternative for the most commonly used in-space propellant (hydrazine) was highly recommended.

Although procedures are in place to allow hydrazine to be managed safely on tightly controlled military reservations and at government-operated launch facilities, the toxicity and explosion potential of hydrazine requires extreme handling precautions that increase operational complexity. Increasingly, with a growing regulatory burden, infrastructure requirements associated with hydrazine transport, storage, servicing, and cleanup of accidental releases are becoming cost prohibitive. As space flight operations continue to shift from government-run organizations to privately funded ventures operating offsite from government-owned test reservations, servicing payloads requiring hydrazine as a propellant becomes operationally infeasible.

These extreme handling precautions generally do not favor hydrazine as a propellant for secondary payloads. Secondary payloads that rely on toxic or hazardous propellants, and present a significant risk to the primary payload, are currently excluded under most launch rules. Thus, because the vast majority of commercial and academic small spacecraft (known as smallsats) rely on "rideshare" or secondary payload launch opportunities, development of a safe and clean replacement for hydrazine-based propulsion systems is especially critical for the emerging commercial space industry.

A useful green replacement for hydrazine must be sufficiently chemically and thermally stable to allow technicians and engineers to safely work with the propellant in a normal "shirtsleeve"
Received 5 October 2016; revision received 19 May 2017; accepted for publication 20 May 2017; published online XX epubMonth XXXX. Copyright (c) 2017 by Utah State University. Published by the American Institute of Aeronautics and Astronautics, Inc., with permission. All request wWwing and permission to reprint should be submitted to CCC (online) to initiate your request. See also AIAA Rights and Permissions www.aiaa.org/randp.

*Professor, Mechanical and Aerospace Engineering Department, 4130 Old Main Hill, UMC 4130. Associate Fellow AIAA. 
commercial environment; but, must reliably combust and have good performance properties. Although the propellant specific impulse is an important consideration, component mass, volume, and propellant conditioning power requirements are even more important as the spacecraft size shrinks. Cryogenic or high freezing point propellants requiring temperature control or significant catalyst-bed heating power input are difficult to engineer for smallsat propulsion applications.

For the past decade, the U.S. Air Force (USAF) and the Swedish Space Corporation's subsidiary Ecological Advanced Propulsion Systems (ECAPS) have been pursuing green propellant alternatives based on aqueous solutions of ionic liquids (ILs) [B]. Ionic liquids are water-soluble ammonium salts that normally exist in solid form at room temperature but melt below the boiling point of water. When dissolved in water, these materials exhibit very strong ion-to-ion interactions. Two of the most promising ionic liquid replacement options for hydrazine are based on ammonium dinitramide [母] and hydroxylamine nitrate (HAN) [7-9]. In August 2011, ECAPS announced the results of a year-long series of in-space tests of a $1 \mathrm{~N}$ thruster comparing their high-performance green propellant (HPGP) to hydrazine on the PRISMA spacecraft platform [9]. ECAPS claims that HPGP delivered equivalent-to-superior performance. NASA recently selected the USAF-developed HAN-based propellant AF-M315E for its Green Propellant Infusion Mission [10].

Unfortunately, there exist several key developmental issues associated with IL-based propellants that make them unsuitable for smallsat applications. The high water content makes IL propellants difficult to ignite. Multiple catalyst systems have been developed to augment IL ignitability; however, room temperature ignition does not currently exist. Catalyst beds must be preheated from 350 to $400^{\circ} \mathrm{C}$ before and during ignition, and this preheat can consume up to 15,000 $\mathbf{J}$ of energy. Catalyst beds and associated heating systems add significantly to the inert mass of the spacecraft, and the high-wattage preheat requirement presents a significant disadvantage for smallsats where power budgets are extremely limited. Finally, at pressures levels below $1000 \mathrm{kPa}$ (145 psia) IL-propellant reaction kinetics are slow [11], and the associated system latencies become large. These latencies may limit the usefulness of IL propellants for pulsed operation on applications such as reaction control systems.

Recent tests of a high-performance green propellant thruster demonstrated full-ignition response times greater than $2.5 \mathrm{~s}$ at pressure levels below $2000 \mathrm{kPa}$ [12]. Clearly, significant technology improvements must occur before IL-based monopropellant chemical propulsion systems can be employed as a primary propulsion unit for smallsats with limited volumes and power budgets, or as part of the reaction control system for smallsats requiring multiple, rapid burn initiation times. With the current state of propulsion technology, the only proven nonhazardous propulsion alternative to hydrazine for rideshare payloads is based on low-performing cold-gas thrusters.

\section{Hybrid Rocket Systems as a Green Space Propulsion Alternatives}

When compared to conventional liquid- and solid-propelled rocket systems, hybrid rockets (where the propellants typically consist of a moderately benign liquid or gaseous oxidizer and an inert solid fuel) possess well-known operational safety and handling advantages. A study by the U.S. Department of Transportation concluded that most hybrid rocket motor designs could be safely stored and operated without a significant risk of explosion or detonation [13]. Thus, such systems offer the potential to significantly reduce operating costs for commercial launch vehicles [13]. Hybrid rockets can be developed to offer higher performance than hydrazine-based systems, and their inherent design safety offers a significant potential for rideshare spacecraft applications. However, in spite of these well-known safety and handling advantages, conventionally designed hybrid rocket systems have not seen widespread commercial use due to several key drawbacks that exist with conventional hybrid system designs.

\section{A. Disadvantages with the Current State of the Art in Hybrid Rocket System}

First, the internal motor ballistics of hybrid combustion produce fuel regression rates that are typically $25-30 \%$ of the rates achieved by composite solid fuel motors in the same thrust and impulse class [14, 15]. These lowered fuel regression rates tend to require high oxidizer flow rates in order to achieve the required thrust levels. This increased oxidizer flow rate results in high oxidizer-to-fuel ratios $(O / F)$ that result in poor mass impulse performance, erosive fuel burning, nozzle erosion, reduced motor duty cycles, and potential combustion instability. To achieve $O / F$ ratios that produce acceptable combustion characteristics, traditional cylindrical fuel ports have been fabricated with very long length-to-diameter ratios. This high aspect ratio results in a poor volumetric efficiency that is incompatible with smallsat applications. Long-profile motors are also more susceptible to lateral buckling when subjected to longitudinal launch loads.

Second, hybrid rockets are "safe" due to the relative propellant stability; however, this stability makes hybrid rocket systems notoriously difficult to ignite. The hybrid rocket ignition source must provide sufficient heat to pyrolize the solid fuel grain at the head end of the motor while simultaneously providing sufficient residual energy to overcome the activation energy of the propellants. Most conventional hybrid rocket systems use pyrotechnic or "squib" charges to ignite a secondary solid-propellant motor for which the high-enthalpy output rate initiates the full hybrid combustion. Such high-energy devices often come with a suite of environmental and objectives risks, as well as operational challenges. Pyrotechnic charges are extremely susceptible to the hazards of electromagnetic radiation to ordnance [15], and large pyrotechnic charges present a significant explosion hazard that is incompatible with rideshare opportunities. Most important, for nearly all applications, pyrotechnic ignitors are designed as "one-shot" devices that do not allow a multiple restart capability. Thus, the great potential for restartable upper stages or in-space maneuvering systems using hybrid propulsion remains largely unrealized. An operational hybrid system with multiple restart capability does not currently exist.

Finally, conventional thermosetting hybrid fuel materials (including hydroxyl-terminated polybutadiene (HTPB), polybutadiene acrylonitrile, and glycidyl azide polymer) must all be mixed from liquid base components, degassed under vacuum, and then cast and cured in a fuel grain mold. With these thermosetting materials scrap or rejected propellant, already having been crosslinked cannot easily be recovered and reused.

These processes require the use of highly toxic iso- and diisocyanates to polymerize and cure the base materials. These isocyanate base materials present a wide variety of environmental safety and occupational health $(\mathrm{ESOH})$ risks, including carcinogenic and detrimental reproductive effects [16]. The U.S. Department of Defense considers these materials to be environmentally unsustainable for large-scale propellant production, and it is actively seeking replacement alternatives [17].

Conventional hybrid rocket "cast and cure" methods are necessarily labor intensive, and high production rates cannot be achieved without a significant manufacturing infrastructure. This labor-intensive manufacture and assembly approach results in highimpact production costs and cannot produce the numbers and varieties of motors required to support what is expected to be a fastgrowing commercial space industry. Hybrid fuel production lags have continually dogged the Virgin Galactic SpaceShipTwo flight program [18].

\section{B. Additive Manufacturing as a Solution to Existing Hybrid Propulsion Technology Disadvantages}

The recent growth of additive manufacturing technologies offers the potential to significantly change materials acquisition methods for the aerospace and defense industries. Typical aerospace supply chains require the maintenance of manufacturing facilities that require significant production rates in order to recover the initial capital costs. For "one-off" or very low-volume production methods, recovery of the initial investment is nearly impossible. 
Recently, both the U.S. Department of Defense and NASA initiated research directives that are investigating the use of modern computer-controlled robotic manufacturing methods to fabricate components additively; that is, components are built one layer at a time from a base material. Modern additive manufacturing methods can support the production rates required for most aerospace/defense applications and offer the potential of improving low-volume component quality, consistency, and performance while reducing development and production costs. Almost no residual material waste occurs when using additive methods. Multiple vendors using these well-developed commercial technologies can produce identical pieces simultaneously, resulting in a "virtual assembly line." These manufacturing advantages are not achievable using conventional methods.

In 2015, NASA concluded the initial tests of the Space Launch System gas generator with the propellant injector three-dimensionally (3-D) printed using additive manufacturing technology $\mathrm{A}$ typical injector system is highly complex and is very tedious to manufacture using conventional methods. Using additive methods took many hours off of the development and manufacturing time. In addition to injectors, it is quite feasible for structural elements for the vehicle stage (including the aft skirt, nozzle enclosure, interstage structure, and all attachment and interface features required for the stage) to also be "printed," possibly as a single component. Multiple small businesses are currently thriving in the additive manufacturing market. If this capability is fully leveraged, the overhead of manufacturing a rocket no longer has to be carried by the aerospace and defense industries alone. The ability to "order" a rocket and have it manufactured and delivered in days to weeks versus months to years can revolutionize the space launch market.

In fact, some "futurologists" believe that 3-D printing signals the beginning of a new style of manufacturing revolution, succeeding the production-line assembly that dominated manufacturing starting in the late 19th century [19]. Using the power of the worldwide Web, it may eventually be possible to send a solid computer model of any product to any place in the world to be replicated by a 3-D printer with "elemental inks" capable of being combined into any material substance of any desired form. This capability would duplicate the functions of the classical Star Trek "replicator."

\section{Additive Manufacturing of Hybrid Rocket Propellants}

Whitmore et al. [20] at Utah State University recently investigated the use of additively manufactured acrylonitrile butadiene styrene (ABS) thermoplastic as a hybrid rocket fuel material. A key outcome was the demonstrated thermodynamic equivalence of ABS to the conventional hybrid rocket fuel HTPB when burned with nitrous oxide $\left(\mathrm{N}_{2} \mathrm{O}\right)$. ABS achieved specific impulse $I_{\mathrm{sp}}$ and characteristic velocity $c^{*}$ that were nearly identical to HTPB. ABS and HTPB fuel regression mass flow rates for cylindrical fuel ports were measured to be nearly identical.

The process used to print these fuel grains is known as fused deposition modeling (FDM). FDM is a 3-D printing method for thermoplastics, where a plastic filament is unwound from a coil and supplies material to a heated extrusion nozzle that heats the material to a near-liquid amorphous state. Once the material is layered down, convective cooling forms a solid material layer. The design starts from a 3-D computer-aided design (CAD) model that is constructed by the developing engineer or technician. Once the CAD "build file" is completed, the model is downloaded to the machine's processor and the specimen is built up one level at a time with layer shapes regulated by a computer numerically controlled mechanism. Almost any conceivable shape can be printed using FDM. Multiple vendors using a well-developed commercial technology can produce identical pieces simultaneously. Because the components are built additively, designs are highly scalable.

ABS has several mechanical properties that make it very attractive as a hybrid rocket fuel. ABS is an inexpensive thermoplastic material

${ }^{\dagger}$ Data available online at http://3dprint/com/95914/nasa-3d-print-f1-rocketengine/ [retrieved XX XXX XXXX]. that is widely mass-produced for a variety of noncombustion applications, including household plumbing and structural materials. ABS is a noncrystalline material with an amorphous structure. As such, ABS does not possess a true melting point but exists in a highly "softened" semifluid state before vaporizing. A typical glass transition temperature for $\mathrm{ABS}$ plastics is $105^{\circ} \mathrm{C}$. This semifluid state exists over a wide temperature range [21]. This melting property makes ABS the most commonly used material FDM printer.

\section{Arc Ignition of FDM-Processed ABS Fuel Grains}

Most important, FDM-processed ABS possesses unique electrical breakdown properties that can be exploited to allow for rapid ondemand ignition. Under normal conditions, ABS possesses a very high electrical resistivity and is not considered to be an electrical conductor [22]; however, as FDM-processed ABS is subjected to a moderate electrostatic potential field, the layered material structure concentrates minute electrical charges that produce localized arcing between material layers. Joule heating from the resulting arc produces a small but highly conductive melt layer. This melt layer allows for very strong surface arcing to occur at moderate input voltage levels: between 200 and $300 \mathrm{~V}$. Additional joule heating from the strong surface arcing causes a sufficient fuel material to be vaporized and seeds combustion when simultaneously combined with an oxidizing flow.

Shortly after this discovery, the author of this paper made several unsuccessful attempts to reproduce a similar phenomenon with other hybrid fuel materials, including HTPB, acrylic, paraffin, and extruded ABS. These experiments also demonstrated that electrical breakdown of FDM-processed ABS occurs at voltages significantly lower than occur with a monolithically fabricated (machined or extruded) article. The extruded or machined ABS does not electrically break down (arc) until voltage levels exceeding $2000 \mathrm{~V}$ are input across the material. This value is roughly an order of magnitude higher that for a similar FDM-processed test article. The observed arcing properties are artifacts of both the grain composite structure due to FDM fabrication and the electromechanical properties of ABS.

The discovery of printed ABS unique electrical breakdown characteristics prompted the invention of an ignition system that takes advantage of the previously described seeding phenomenon. Figure 1 illustrates the top-level concept, where two electrodes are embedded in an ABS fuel grain segment. The layered structure of the FDM-processed ABS provides local surface features of very small radius. The effect is to produce a large ensemble of "electrodes" with a gap distance on the order of fractions of a millimeter. The inset image shows the electrostatic arc as it moves along the fuel grain surface. Pyrolized gas can also be observed.

The particular orientation of the FDM-processed material layers was found to have a significant effect on the arcing process. Horizontal layering with the build layers laid down perpendicular to the direction of oxidizer flow tends to produce the best results for system ignition. To qualitatively assess this effect, three conical grains were manufactured: two grains using a Stratasys Dimension ${ }^{\circledR}$ 3-D FDM printer, ${ }^{1}$ and the other grain machined from extruded ABS stock material. The grains were printed using commercially available Stratasys ABS Plus ${ }^{\circledR}-340$ feed stock. One FDM-processed ignitor grain was printed "vertically stacked," that is, with deposition layers printed parallel to the longitudinal axis of the motor and direction of oxidizer flow. The second grain was printed "horizontally stacked," with deposition layers perpendicular to the longitudinal axis of the motor and perpendicular to the direction of oxidizer flow.

As demonstrated by Whitmore et al. [23], 24], after several arcbreakdown cycles, the vertically stacked ignitor grain ceased to visibly arc. To evaluate this test result, the grain was cut along the longitudinal axis. Patterns of heavy char indicated that an alternate path between the electrodes had formed, and any circuit closure was

${ }^{\ddagger}$ Anon., "Dimension 1200es, Durability Meets Affordability," http://www stratasys.com/3d-printers [retrieved 25 Dec. 2015].

${ }^{\S}$ Data available online at http://www/stratasys.com/materials/fdm [retrieved 18 June 2015.] 

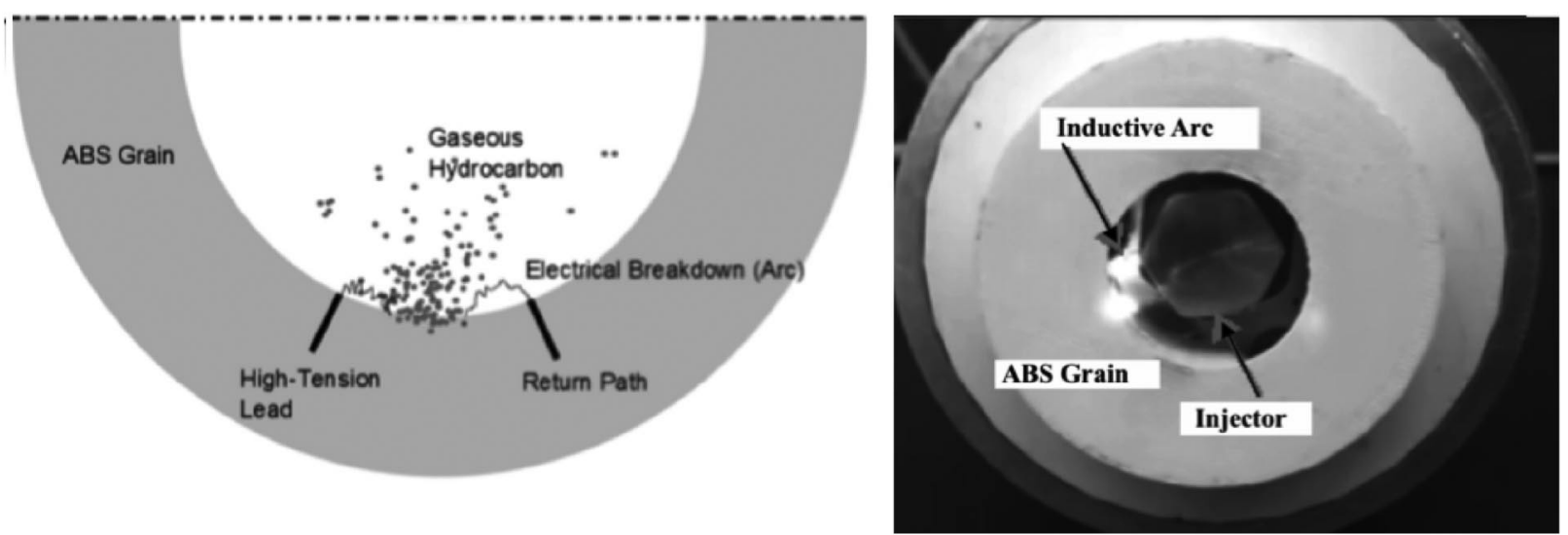

Fig. 1 Arc-ignitor joule heating concept.

occurring internal to the grain surface. Because the loop was closed internal to the grain surface, fuel pyrolysis and the resulting vapor generation did not occur. This behavior was observed for several vertically stacked test specimens. This behavior did not occur in any of the horizontally stacked specimens tested, and it indicates that horizontal stacking is the preferred method of manufacture.

\section{Arc-Ignition Assessment of Other Commercially Available 3-D Print Materials}

Whitmore et al. 25, recently investigated multiple commercially available $3-\mathrm{D}$ printable materials to search for equivalent or possibly superior fuel alternatives to ABS. The study did not attempt to design or optimize the plastic materials but, instead, simply evaluated the effectiveness of common commercially available 3-D printer materials. Test specimens included photopolymers processed using polyjet (stereolithography) and FDM printing. Comparison metrics included the general ability for the electrostatic arcing, material pyrolysis rate, dissipated power, characteristic velocity, and ability for multiple restarts. Initially, an ensemble of eight commonly available "printable" polymers was evaluated, and only four printable materials (high- and low-density printed ABS Plus-340, VeroClear ${ }^{\circledR}$, and white polycarbonate) were found to possess effective "sparking" properties. In follow-on burn tests, only high- and low-density ABS Plus-340 and VeroClear performed effectively as fuel materials. White polycarbonate would not ignite using the arc method. High-density ABS Plus exhibited the best overall ignition properties and characteristic velocity. Follow-on development tests to be reported in the paper used this ABS Plus-340 material exclusively.

\section{Regression Rate Enhancement Using Helical Fuel Port Structures}

As mentioned previously, FDM-processed hybrid fuel grains can be fabricated with an almost infinite range of fuel port shapes, allowing for significant enhancement of burn properties and combustion efficiencies. Bath [27] previously investigated the 3-D printing and burning of ABS fuel grains with complex port geometries and the development of software capable of modeling and predicting the regression of arbitrary cross sections. Of particular interest are helical fuel structures for which the centrifugal flow patterns have shown the potential to significantly increase the fuel regression rate. Fuller et al. at [28] and Arnold et al. [29] both previously achieved success with burning printed fuel grains with embedded helical and swirl patterns. Both studies demonstrated the qualitative increase in the regression rate. The additive manufacturing process used in [28, 29] was stereolithography and not FDM.

\footnotetext{
IData available online at http://www/stratasys.com/materials [retrieved 15 Nov. 2015].

**Data available online at http://www/stratasys.com/materials/polyjet [retrieved 18 June 2015.]
}

It is well known that helical pipe flows have the effect of significantly increasing the local skin-friction coefficient. Helical flows also introduce a centrifugal component into the flowfield. This centrifugal flow component suppresses the well-known "wall blowing" effect [30] where heat transfer from the flame to the wall is reduced by the radial flow emanating from the regressing fuel grain. The centrifugal flow induced by the helical fuel port thins the wall boundary layer, bringing the flame zone closer to the wall surface and increasing the flame diffusion efficiency. A series of tests were performed to evaluate the effectiveness of helical fuel port structures in increasing the fuel regression rate. The results of these helical port tests, demonstrating regression rate amplification exceeding a factor of three, are presented in Sec. III.G.

\section{System Prototype Test Results}

A series of incremental developmental tests were performed to determine the most appropriate geometry for the arc-ignition fuel grain. References [23.24] describe these developmental experiments in detail. Two fundamental generations of prototypes were built and tested. The first-generation ignition system was designed as an external "strap-on" ignitor for an existing 98-mm-diam hybrid motor. The strap-on ignitor replaced the pyrotechnic charges that were previously used for the motor ignition system. The secondgeneration system reconfigured the strap-on ignitor to move the system inside of the combustion chamber with the ignitor fuel grain section as an integral part of the main motor fuel grain.

\section{A. Second-Generation Embedded Arc-Ignitor Development and Testing}

The second-generation ignitor concept was developed to overcome multiple practical shortcomings associated with the firstgeneration prototype strap-on ignitor design. Rather than house a small separate ABS fuel grain mounted on top of the $98 \mathrm{~mm}$ motor cap, channels for conductive paths were built into additively manufactured precombustion chambers. These chambers were then "plugged into" a main propellant grain and inserted into the motor tube. For these tests, the oxidizer was gaseous oxygen (GOX). Later tests successfully replaced GOX with nitrous oxide. Vacuum tests were also successfully performed. Vacuum test results are also summarized in the final section of this paper. Reference [31] reports the nitrous oxide text results.

Because the primary objective of this test campaign was to optimize the arc-ignitor fuel grain design, it was deemed too costly and time consuming to manufacture multiple full-scale $98 \mathrm{~mm}$ hybrid fuel grains; thus, as a lowered-cost alternative, an existing $98 \mathrm{~mm}$ motor cap previously used for hybrid motor testing was adapted to fit into a short $10.2 \mathrm{~cm}$ hybrid motor section. Figure 2 shows an exploded view of this developmental unit, dubbed as "little Joe." The design was engineered such that nozzle geometries could be quickly varied to provide a range of internal chamber pressure conditions. Finally, the GOX injector feed pressure could be modified using a manually adjusted pressure-reducing regulator. 


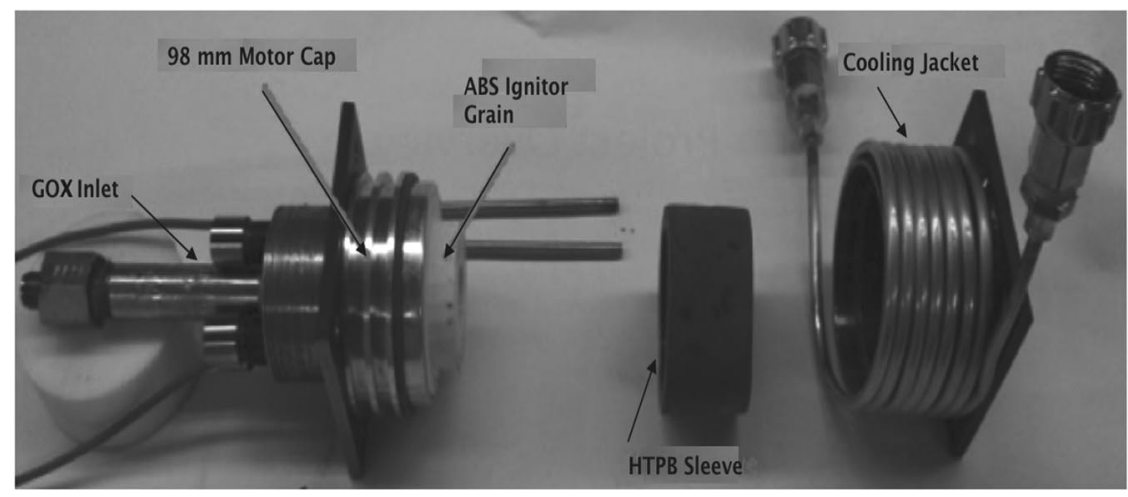

Fig. 2 Exploded view of the little Joe ignitor test motor.

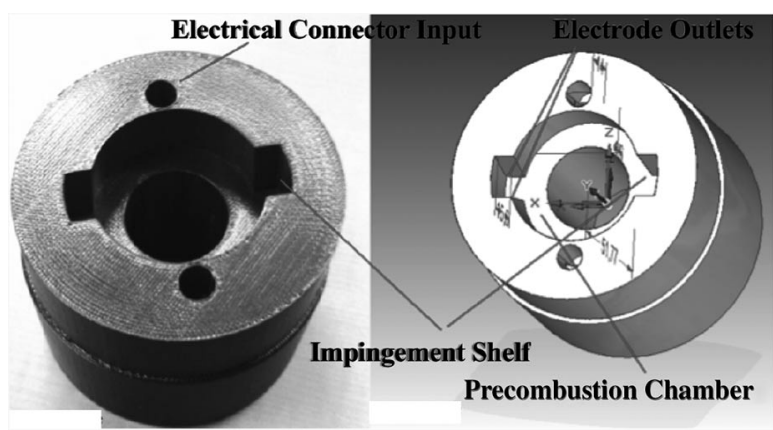

Fig. 3 Dual-shelf ignitor grain.

Three different ignitor grain geometries were evaluated. These configurations were 1) a conical converging section, 2) a steppedcylindrical section with a flow impingement "shelf," and 3) a steppedcylindrical section with dual impingement shelves. The first two geometries were evaluated using a straight single-port injector, and the final dual-shelf geometry was tested using coaxial injector with an axial port and two side injection ports. During this testing campaign, only configuration 3 performed in a reliable and effective manner. Those results are presented in the following paragraphs.

The successful "configuration 3" grain geometry featured a "dualshelf" design with a coaxial injector plug fabricated from a threaded brass insert with drilled axial and side injection ports. The axial center port diameter was $1 / 8$ th in. $(0.325 \mathrm{~cm})$, and the two side injection ports were each $1 / 16$ th in. in. $(0.16 \mathrm{~cm})$ diameter. This design directs two-thirds of the oxidizer flow downstream into the combustion chamber and one-third of the flow onto the impingement shelves. These features were intended to shorten the combustion latencies exhibited by the earlier configurations. Figure 3 shows the dual-shelf ignitor grain design.

Figure 4 presents representative test results from the dual-shelf ignitor grain tests. Here, the thrust (Fig. 4a), chamber pressure (Fig. 4b), ignition current (Fig. 4a), and thruster input/output power time histories (Fig. 4 d) are plotted for multiple motor burns. During this test series, the upstream regulator set pressure was gradually increased so as to produce chamber pressures levels that gradually rose from near-ambient pressure to greater than 150 psia. At the lowest chamber pressures, as the spark power was activated, the fuel grains would smolder and a trickle of pyrolized hydrocarbon could be observed exiting from the nozzle. Only once the measured chamber pressure level reached approximately 28 psia (indicated by the dashed line of Fig. (4) was full ignition achieved.

The ignition system power processing unit was based on the UltraVolt ${ }^{\circledR}$ AA-series line of high-voltage power supplies (HVPSs). . Off-the-shelf units with output capacities from 4-30 W are available. 0 These tests employed a 6 W HVPS unit. The ignition spark signal is initiated by a commanded TTL-level signal that provides a current-

thData available online at http://www/ultravoliccom/uv_docs/HP8C30CDS.pdf [retrieved 9 Oct. 2014]. limited (6.5 mA) high-voltage output of up to $1 \mathrm{kV}$. When the ignition signal is initiated, the resulting "dump voltage" is a result of the actual resistance path that the current finds along the fuel grain surface.

In the plotted ignition sequences, the ignition spark was initiated at "time zero," and the GOX run valve was opened 1/2 s (500 ms) later. The spark power overlaps the run valve opening by an additional $500 \mathrm{~ms}$. The $500 \mathrm{~ms}$ prelead for the ignition spark was set as a matter of convenience to ensure reliable motor ignition for this test series performed using the low-power 6 W HVPS. Later tests demonstrated that, when the $30 \mathrm{~W}$ HVPS was used, significantly shorter spark times could be employed. For this test series, it can be observed that the input power required for ignition is less than $4 \mathrm{~W}$ and the generated power exceeds $60 \mathrm{~kW}$. The consumed ignition power for each burn is less than $4 \mathrm{~J}$.

This input power level was contrasted to the required catalyst bed preheat power for the PRISMA spacecraft, which used the LMP$103 \mathrm{~S}$ propellant. To reach the required $350^{\circ} \mathrm{C}$ catbed preheat temperature, a $10 \mathrm{~W}$ heater was installed in the PRISM spacecraft. Depending on the relative sun angle, the duty cycle of the heater varied from 67 to $93 \%$. The time required for $9.25 \mathrm{~W}$ catbed preheating to $340^{\circ} \mathrm{C}$ in flight varied from 600 to $720 \mathrm{~s}$. Operationally, the preheating time was set conservatively to $30 \mathrm{~min}$ before enabling the thruster for firing. Because of the potential for freezing the water component of LMP-103S, the average temperature of the propellant tank was maintained at an operating temperature near $20^{\circ} \mathrm{C}$. Each ignition preheat cycle consumed as much as $25 \mathrm{~kJ}$ of energy [32].

For the highest regulator pressure setting ( $350 \mathrm{psig}$ ), the grain would smolder for approximately $25-50 \mathrm{~ms}$ before ignition onset and rapid chamber pressure rise occurred. After ignition onset, full chamber pressure was achieved in approximately $400 \mathrm{~ms}$. As observed by the tail off pressures after run valve closure, approximately $200 \mathrm{~ms}$ of the combustion latency was due to the natural acoustical response time of the combustion chamber. The remaining $200 \mathrm{~ms}$ of latency was due to the kinetics of the combustion process and was primarily a result of the initial combustion chamber design. As will be demonstrated by data to be presented in later sections of this paper, the slow response time of the initial prototype was due to the very short fuel port aspect ratio where the initial port diameter was nearly same dimension as the port run length. The result was a very high $\mathrm{O} / \mathrm{F}$ that resulted in a slow ignition response.

\section{B. Integrated Motor Testing on 75-Millimeter Laboratory-Weight Prototype}

The GOX/ABS ignition tests were concluded by integrating the dual-shelf ignitor design into the top end of a laboratory-scale $75 \mathrm{~mm}$, $170 \mathrm{~N}$ thrust hybrid rocket motor. References [33, 34] present detailed descriptions of the test apparatus and complete test results. Figure 5 shows the motor layout with the integrated ignitor section. The pictured motor configuration also shows an embedded helical structure designed to increase the regression rate and combustion efficiency. The design takes advantage of FDM processing to build the ABS ignitor and fuel grain sections with "snap-together" interlocks that allow individual grain segments to be manufactured separately and then assembled for combustion. 

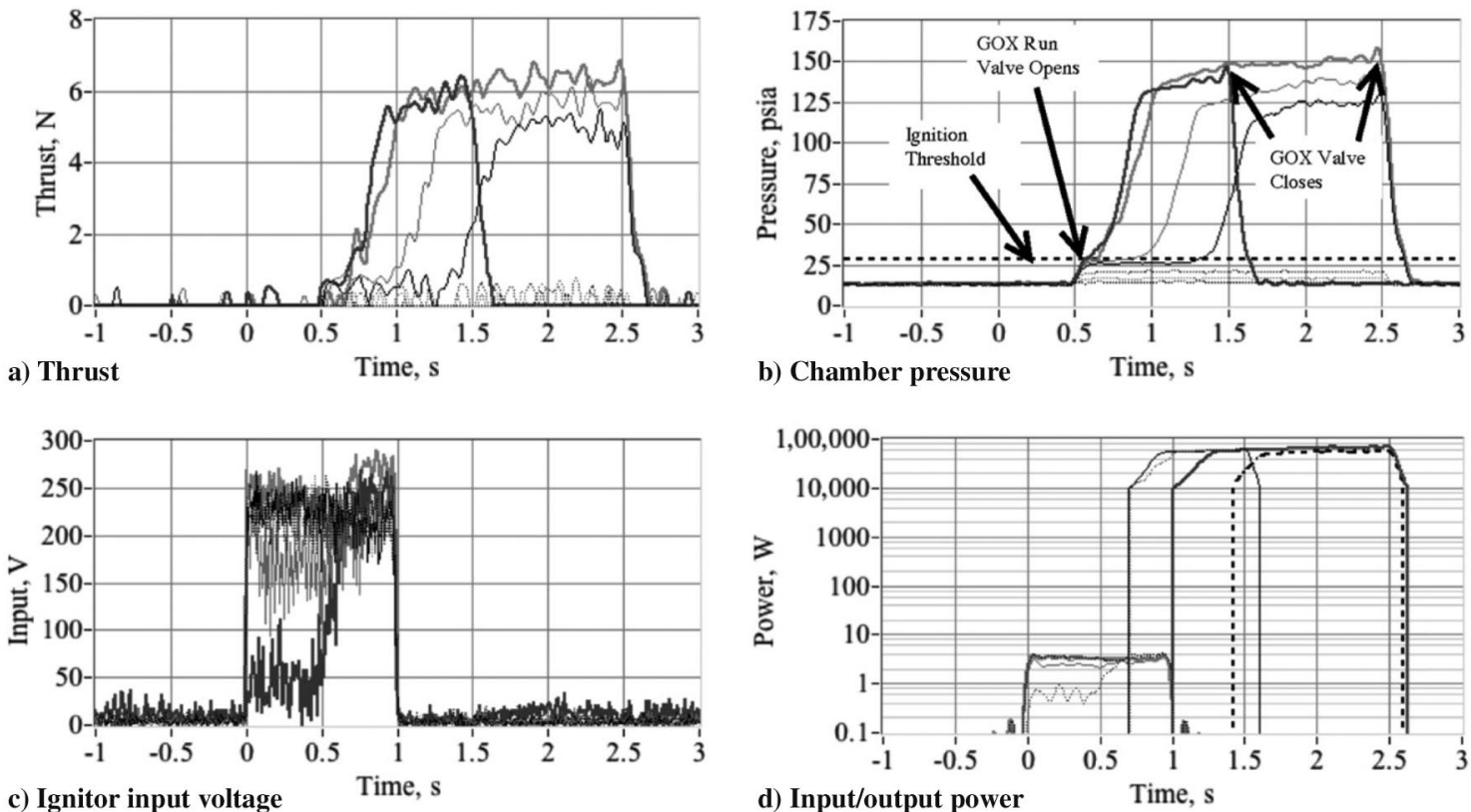

Fig. 4 Dual-shelf ignitor, coaxial injector test results.

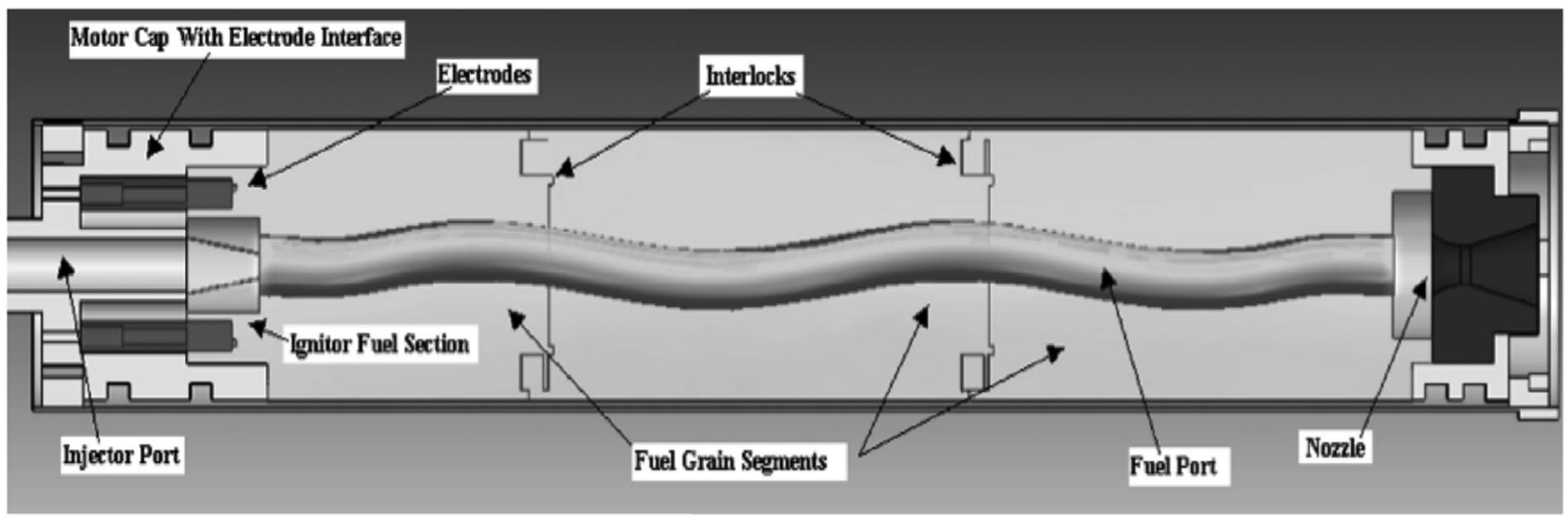

Fig. 5 Hybrid motor with integrated ignitor and interlocking fuel segments.

Figure 6 shows the motor test-firing in the Utah State University (USU) Propulsion Research Laboratory's on-campus test cell. To ensure ignition reliability and increase response fidelity during this test series, the 6 W HVPS was replaced with a considerably more powerful $30 \mathrm{~W}$ unit. The port aspect ratio was also significantly longer than for the previously described little Joe ignitor prototype tests.

Figure 7 compares the typical thrust, chamber pressure, ignitor current, and input power time histories for three consecutive "handsoff' burns of the embedded ignitor grain. For this test series, the spark signal was initiated at time zero, and the run valve was opened $750 \mathrm{~ms}$ later. The spark overlap after combustion starts is approximately $250 \mathrm{~ms}$. The response fidelity of the integrated system is significantly

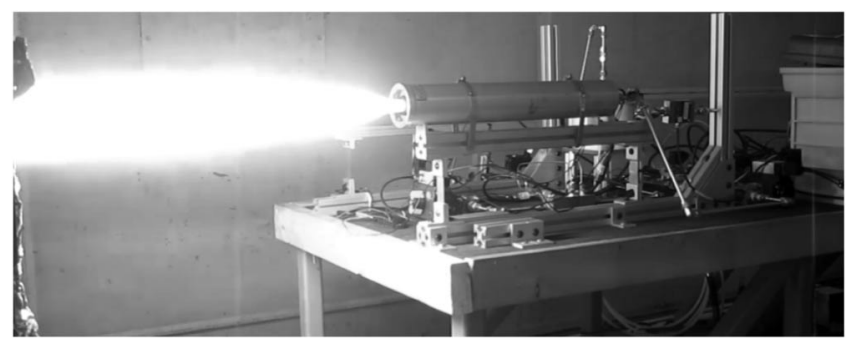

Fig. 6 Image of $75 \mathrm{~mm}$ motor with integrated ignitor firing in USU test cell. better than was observed for the patched-together little Joe test apparatus. The burn profiles exhibited excellent run-to-run consistency with low deviations in both thrust and chamber pressure. For all three burns, the response time from the opening of the GOX valve to full chamber pressure was less than 80-100 ms.

For all three examples, the mean input power required for ignition is less than $4 \mathrm{~W}$, with a maximum power draw of less than $8 \mathrm{~J}$. Each ignition cycle requires less than $4 \mathrm{~J}$ of input energy. For these tests performed under ambient pressure conditions, the motor features a semioptimized nozzle with an expansion ratio of 3.5. The mean delivered $I_{\mathrm{sp}}$ at ambient conditions is $228.7 \mathrm{~s}$.

\section{Regression Rate Enhancement with Helical Port Structures}

At the conclusion of the ignition test series, the $75 \mathrm{~mm}$ motor was adapted to investigate the effects of using different helical port structures to enhance the fuel regression rates. References [33, 34] presented detailed descriptions of the test apparatus and complete test results. References [34]35] also developed a detailed analytical model for the helical enhance process, to be described in the following paragraphs.

It is well known that helical pipe flows with cylindrical ports show significantly increased end-to-end pressure losses when compared to flows through straight pipes with identical cross sections. Thus, helical flows have the effect of significantly increasing the local skin-friction coefficient. Helical flows also introduce a centrifugal component into the flowfield. In hybrid rocket applications, this centrifugal component 


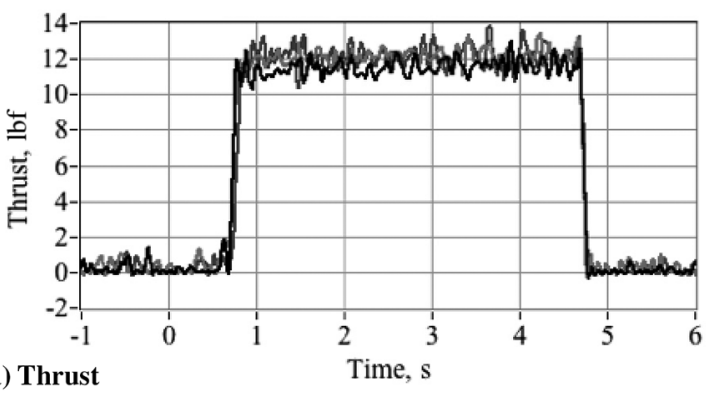

a) Thrust

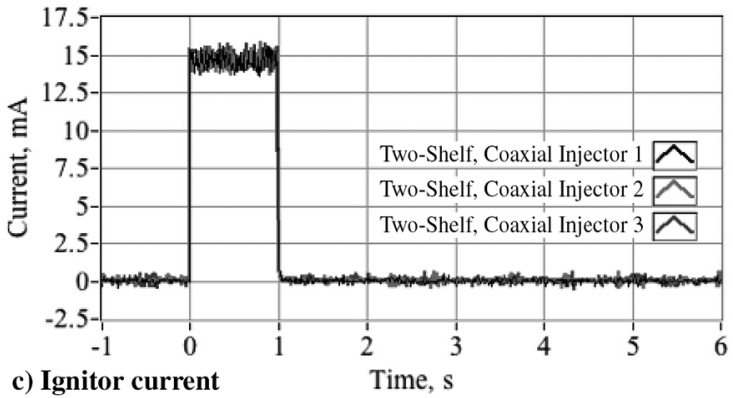

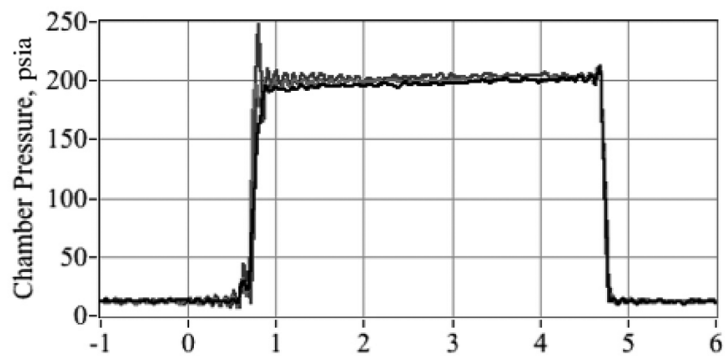

b) Chamber pressure Time, $\mathrm{s}$

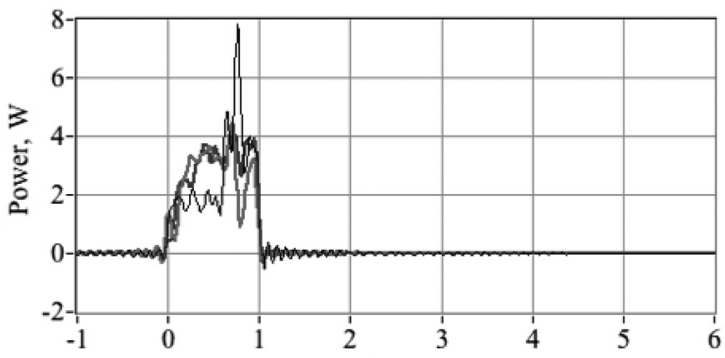

d) Input power

Fig. 7 Embedded arc ignition of $75 \mathrm{~mm}$ hybrid motor.

has the effect of pushing the flame zone closer to the wall surface and increasing the flame diffusion efficiency. In other words, a helical port serves to both increase the surface skin-friction coefficient and simultaneously reduce the wall blowing effect, leading to a significant enhancement of the overall regression rate.

For this series of tests, the motor configuration of Fig. 5 was used, and the test fuel grains were manufactured simultaneously as interlocking segments on a Stratasys Dimension 1200es 3-D FDM printer from standard density $\left(0.975 \mathrm{~g} / \mathrm{cm}^{3}\right)$ ABSplus- 340 feedstock material. Joints were bonded using commercial-grade $A B S$ pipe joint cement. Six fuel grain geometries (a straight bore-cylindrical grain and five helical ports with varying helix geometries) were tested. In all 31, static firings were performed as a part of this testing campaign.

The helical structure is defined by three parameters: the nominal fuel port diameter $D_{0}$, the helix loop diameter $d$, and the helix pitch length $P$. The pitch length is defined as the distance between the centerlines of two consecutive helical wraps, where $L$ is the port length and $N$ is the number of rotations of the helical centerline:

$$
P=L / N
$$

The helix also serves to increase the internal run length of the fuel port, increasing the end-to-end flow Reynolds number and fuel surface area. The total run length $S$ of the helix centerline is

$$
S=2 \pi N \sqrt{\left(\frac{d}{2}\right)^{2}+\left(\frac{P}{2 \pi}\right)^{2}}
$$

In Eqs. (7) and (8), $N$ is the number of rotations along the helix length. The increased internal port length allows for a significantly more compact fuel grain form factor.
The first fuel grain (fuel grain 0) tested had a cylindrical port and established the baseline for the regression rate of the propellants. The next three grains (fuel grain 1, fuel grain 2, and fuel grain 3) tested featured a total grain length of $35.98 \mathrm{~cm}$ with approximately 2.5 turns along the length of the fuel port. Excluding the postcombustion chamber, the resulting pitch distance was $15.24 \mathrm{~cm}$. The final two grains investigated the effects of both the total fuel grain length and pitch distance on the regression rate. Grain 4 Was identical to grain 1, except that is was truncated at a $22.86 \mathrm{~cm}$ length. The final grain (grain 5) was also truncated at a $22.85 \mathrm{~cm}$ length, but it featured 8.5 total rotations and a pitch length of $2.7 \mathrm{~cm}$. Table 1 summarizes the parameters of these fuel grains. Column 6 of this table also lists the helical "pitch ratio," which is defined as the ratio of the initial helix loop diameter multiplied by the number of loops divided by the initial fuel port diameter:

$$
P_{R}=\frac{L}{P} \cdot \frac{d}{D_{0}}=N \cdot \frac{d}{D_{0}}
$$

The fuel regression rate is shown to exhibit a strong correlation to the initial fuel port $P_{R}$.

Although the real-time thrust-stand oxidizer mass flow and motor mass measurements were obtained, for this testing campaign, each grain was burned multiple times and the motor was disassembled after each test to allow intermediate mass measurements as a check on the accuracy of the real-time measurements. The fuel regression rate was calculated from the differences between the measured oxidizer and nozzle exit mass flows according to Eq. (\#).

The test stand for this series of experiments directly measured the oxidizer mass flow using an inline venture flow meter. Unfortunately,

\begin{tabular}{|c|c|c|c|c|c|c|}
\hline \multirow[b]{2}{*}{ Grain no. } & \multicolumn{6}{|c|}{ Fuel port parameters } \\
\hline & Port length $L, \mathrm{~cm}$ & Pitch length $P, \mathrm{~cm}$ & Initial port diameter $D_{0}, \mathrm{~cm}$ & Initial helix diameter $d, \mathrm{~cm}$ & Pitch ratio, $(N * d / D)$ & No. of burns \\
\hline 0 & 35.98 & 15.24 & 1.524 & -- & -- & 3 \\
\hline 1 & 35.98 & 15.24 & 1.524 & 0.762 & 1.177 & 5 \\
\hline 2 & 35.98 & 15.24 & 1.524 & 1.143 & 1.770 & 5 \\
\hline 3 & 35.98 & 15.24 & 1.524 & 1.524 & 2.361 & 6 \\
\hline 4 & 22.86 & 15.24 & 1.524 & 0.762 & 0.750 & 5 \\
\hline 5 & 22.86 & 2.7 & 1.524 & 1.143 & 6.350 & 6 \\
\hline
\end{tabular}
the fuel mass flow rate was not measurable in real time. Thus, for this

Table 1 Fuel grain geometries for helix regression tests 
testing campaign, the "instantaneous" fuel regression rate was calculated from the mass flow rate:

$$
\overline{\dot{r}}=\frac{\dot{m}_{\text {fuel }}}{2 \cdot \rho_{\text {fuel }} \cdot \pi \cdot \bar{r} \cdot L}=\frac{\dot{m}_{\text {total }}-\dot{m}_{\text {ox }}}{2 \cdot \rho_{\text {fuel }} \cdot \pi \cdot \bar{r} \cdot L}
$$

The fuel mass flow rate was calculated as the difference between the measured nozzle exit and oxidizer mass flow rates. The nozzle exit mass flow time history was calculated from the measured chamber pressure time history, nozzle exit area, and exhaust gas properties using the one-dimensional choking mass flow equation [36]:

$$
\dot{m}_{\text {total }}=A^{*} \cdot P_{0} \cdot \sqrt{\frac{\gamma}{R_{g} \cdot T_{0}}\left(\frac{2}{\gamma+1}\right)^{((\gamma+1) /(\gamma-1))}}
$$

Integrating Eq. (4) from the initial condition solves for the longitudinal mean of the instantaneous fuel port diameter:

$$
\bar{r}(t)=\sqrt{r_{0}^{2}+\int_{0}^{t} \frac{\dot{m}_{\text {fuel }} \cdot \mathrm{d} t}{\rho_{\text {fuel }} \cdot \pi \cdot L}}
$$

Using the estimated fuel port radius and the measured oxidizer mass flow rate, the mean longitudinal oxidizer mass flux is estimated as

$$
\bar{G}_{\mathrm{ox}}=\frac{\dot{m}_{\mathrm{ox}}}{\pi \cdot r_{(t)}^{2}}
$$

For each data point in the burn time history, two-dimensional tables of thermodynamic and transport properties were interpolated to calculate the gas constant $R_{g}$, ratio of specific heats $\gamma$, and flame temperature $T_{0}$. The exhaust plume properties were estimated using the method developed in [20] with the measured chamber pressure $P_{0}$, combustion efficiency $\eta^{*}$, and mean $O / F$ ratio as independent lookup variables. Whitmore et al. [20] used the NASA CEA code [37] to perform the equilibrium calculations.

Each fuel grain was burned multiple times to allow interim mass measurements between burns. The corresponding oxidizer mass consumed was calculated by integrating the Venturi mass flow time history over the burn duration. The mean $O / F$ ratio over the burn duration was estimated by dividing the consumed oxidizer mass by the consumed fuel mass. By adjusting $\eta^{*}$, the flame temperature was scaled:

$$
T_{0_{\text {actual }}}=T_{0_{\text {ideal }}} \cdot\left(\eta^{*}\right)^{2}
$$

to adjust nozzle exit mass flow and the resulting consumed fuel mass flow,

$$
\Delta m_{\text {fuel }}=\int_{0}^{T}\left(\dot{m}_{\text {total }}-\dot{m}_{\text {ox }}\right) \cdot \mathrm{d} t
$$

Adjusting input combustion efficiency upward has the effect of increasing the calculated fuel mass consumption, and downward decreases the calculated fuel mass consumption. The fuel mass flow calculation starts with an assumed combustion efficiency of $\eta^{*}=0.90$. The calculations of Eqs. (49) were iterated, adjusting $\eta^{*}$ until the calculated fuel mass equaled the measured mass within a prescribed level of accuracy $(1 / 2 \%)$. For all runs, the regulator pressure and injector port diameter were preset to choke the injector flow and ensure a constant oxidizer mass flow of $40 \mathrm{~g} / \mathrm{s}$ [33.34]. Choking the injector flow ensured very low run-to-run variability in the oxidizer mass flow rate, and it significantly reduced the risk of incurring injector feed coupling instabilities during combustion [38].

Figure 8 plots the fuel regression rates as a function of the longitudinal mean of the oxidizer mass flux. Also plotted for each fuel grain are exponential curve fits of the form

$$
\dot{\bar{r}}=a \cdot \bar{G}_{\mathrm{ox}}^{n}
$$

When compared to the cylindrical fuel port grain, all of the helical grains exhibit a significant increase in the mean regression rate. Qualitatively, it is reasonable to infer that the helical loop diameter $d$, pitch distance $P$, initial fuel port diameter $D_{0}$, and fuel port length $L$ all have distinct effects on the resulting regression rate profile. The overall correlation is established by plotting the best-fit burn exponents of Fig. 8 against the pitch ratio parameter defined by Eq. (2). Figure 7 presents these results. The measurements are well correlated.

In Fig. 8, the high mass flux occurs early in the burn sequences where the fuel port is still quite helical, and the resulting centrifugal flow effects push the flame zone closer to the wall. As the port burns and the mass flux drops, the helical structure also regresses both radially and longitudinally, gradually becoming more cylindrical in shape. The resulting drop in centrifugal force as the port becomes circular allows pyrolized fuel leaving the grain surface to push the flame zone away from the wall and reduces the effects of heat transfer to the walls. The regression rate drops accordingly.

The correlation of Fig. 9 explains why the grain 4 curve appears to be "out of place" on Fig. 6 . Even though the helical parameters of grain 4 are identical to those of grain 1, the lower number of turns along the grain length for grain 4 reduces the overall effectiveness of the helix. Correspondingly, the short pitch length fuel grain where the helical loops are spaced closely together and longitudinally shows the highest initial regression rate and most rapid regression rate drop over time. Finally, because the helical loops in the fuel grain progressively burn together with time, the fuel port becomes

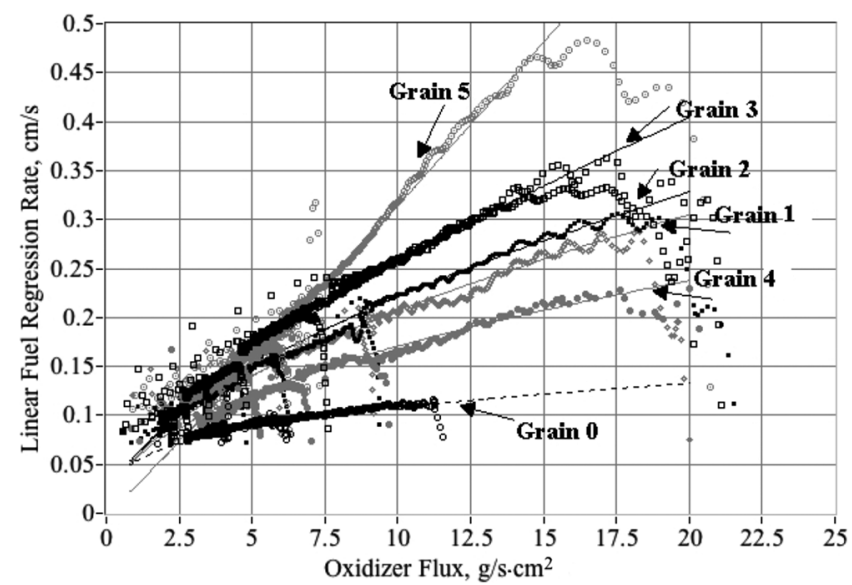

Fig. 8 Regression rate comparison for straight-bore and helical grains.

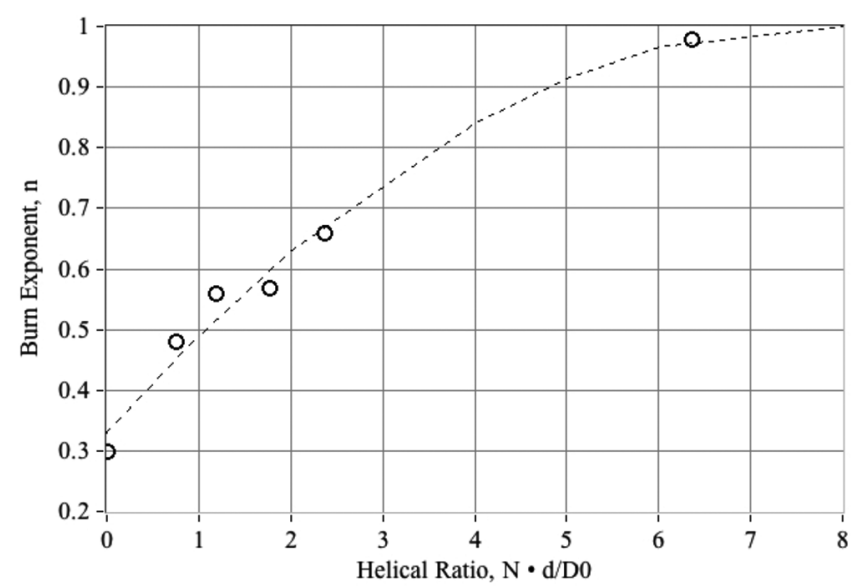

Fig. 9 Curve-fit exponent plotted against helical pitch ratio. 


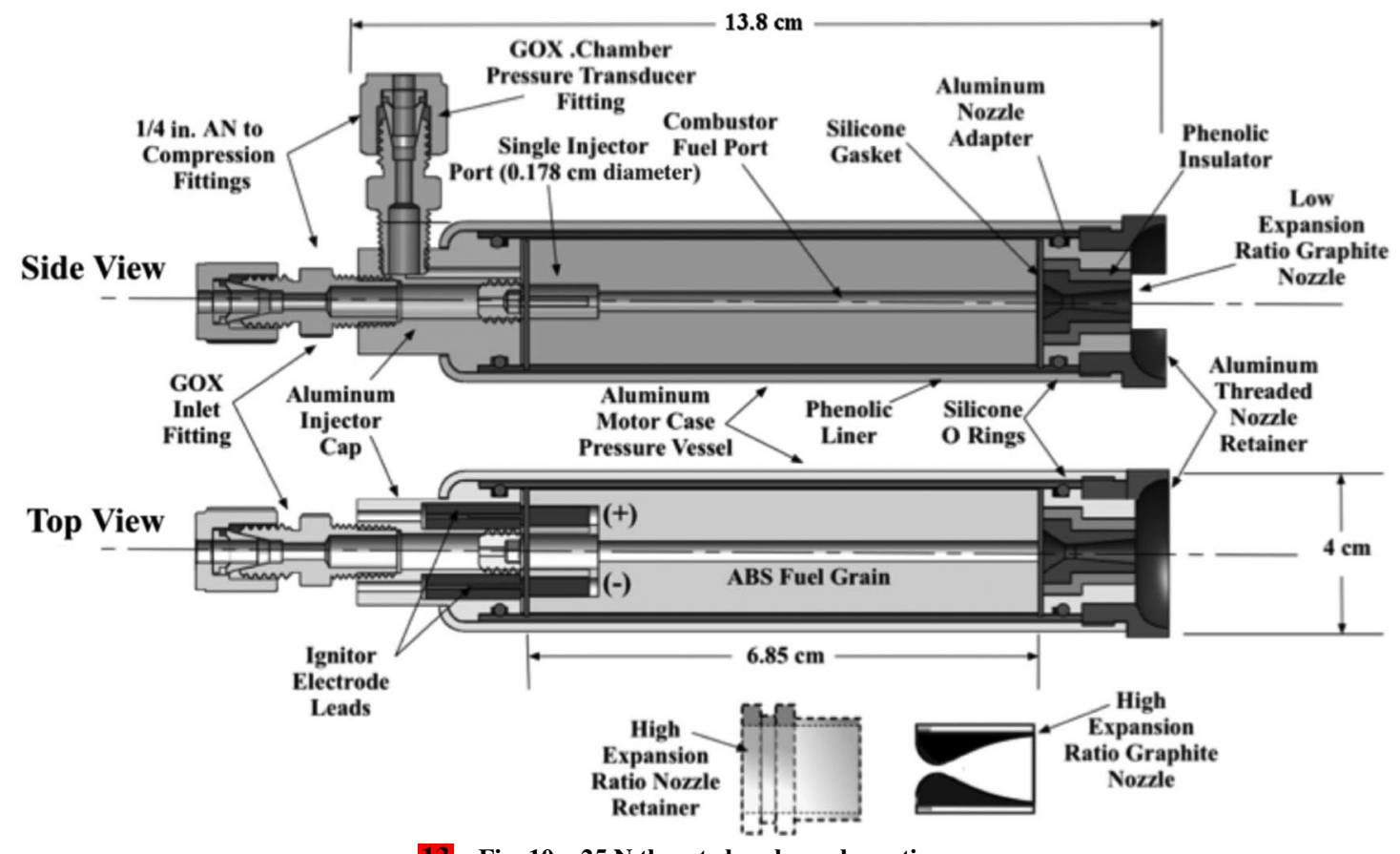

Fig. $1025 \mathrm{~N}$ thrust chamber schematic.

more and more like a cylinder. Conveniently, this effect reduces the potential for excessive unburned fuel "slivers" at the end of the burn lifetime of the fuel grain.

\section{Flight-Weight System Development and Ground Testing}

After proof-of-concept tests with the ignitor and laboratory-scale integration tests were completed, an effort was made to scale down the thruster to a flight-weight system that would be generally applicable for smallsat operations. An analytical hybrid flow model [39] was used to design a flight-weight unit with a desired $25 \mathrm{~N}$ thrust level. Figure 10 shows the thrust chamber schematic. The motor systems consist of 1) a thrust chamber, 2) phenolic line, 3) motor cap with integral oxidizer injector, 4) fuel grain with embedded electrodes, 5) graphite nozzle, and 6) nozzle retainer. The printed fuel grains were fabricated from Stratasys ABSplus- $340^{\circledR}$ feedstock. Figure 11] shows the scaled fuel grain with integrated electrodes for the arc-ignition system.

Both ambient pressure and vacuum tests were performed. The following subsections describe these test results. Table 2lists the key motor parameters. Table 3 summarizes the ambient and vacuum test results. For ambient test conditions, the nozzle expansion ratio os 2.1:1, and it was approximately optimal for the test altitude in Logan, Utah. The vacuum test nozzle expansion ratio was 9:5:1, and it was approximately optimal for the expected vacuum chamber pressures that could be achieved with the motor firing. The nozzles were machined from a single piece of graphite. Figure 12 shows the laboratory apparatus used to test the flight-weight system including the 3-D schematic (Fig. 12a) and the plumbing and instrumentation diagram (P\&ID) (Fig. 12b). Whitmore and Mathias [40] gave a complete description of the test stand and the instrumentation system used to collect these measurements.

\section{Ambient Pressure Tests of the Flight-Weight System}

Figure 13 shows the prototype flight-weight thruster during a typical ground-test firing using the 2.1:1 expansion ratio nozzle. Figure 14presents results from a typical test with $41 \mathrm{~s}$ pulses. Plotted are the thrust as measured by the load cell and calculated from the chamber pressure (Fig. 14a); the chamber, nozzle exit, and ambient pressure (Fig. 14b); the nozzle exit, oxidizer and fuel mass flow (Fig. 14c); the specific impulse as calculated from the thrust, chamber pressure, and total mass flow (Fig. 14d); the ignitor input voltage (Fig. 14e); and the ignitor input power and total input energy

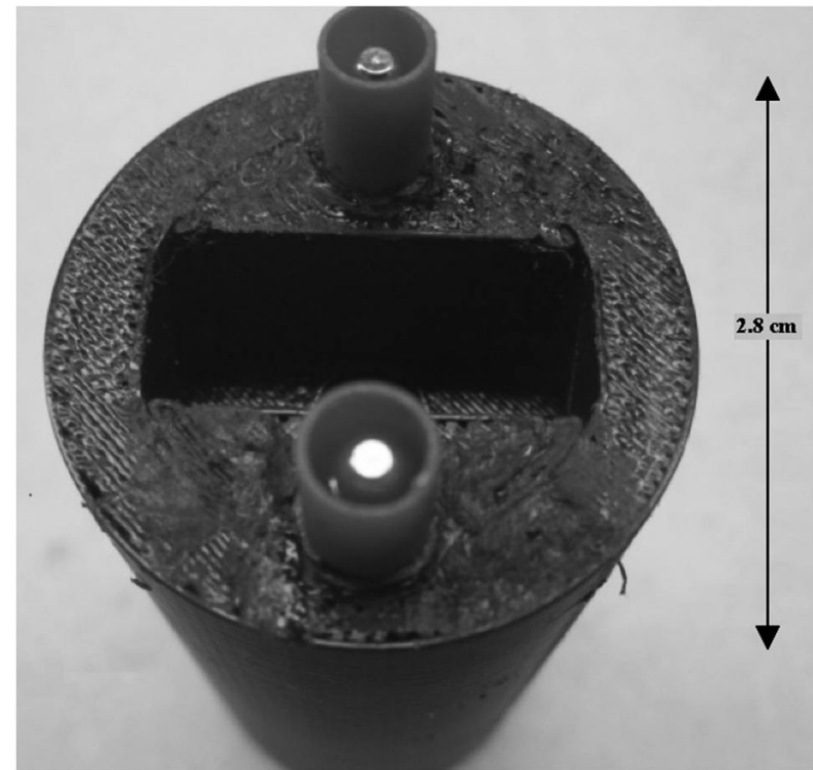

Fig. 11 Scaled-down ABS fuel grain with integrated spark ignitor.

(Fig. 14f). The thrust and specific impulse values calculated from the measured chamber pressure are also plotted as a "sanity check" against the heavily filtered values measured using the load cell. Note that, in Fig. 14d, the nozzle exit pressure is slightly greater than the ambient pressure levels, indicating a slightly suboptimal, underexpanded nozzle configuration. The ignition energy required to complete the four-burn sequence is slightly greater than $6.0 \mathrm{~J}$.

Multiple ambient test sequences were performed, and an ensemble of 50 successful $1 \mathrm{~s}$ burns was obtained. Almost no nozzle erosion was observed during the 50-burn ambient test campaign. The mean thrust level was approximately $22.6 \mathrm{~N}$ with a burn-to-burn standard deviation of $\pm 1.2 \mathrm{~N}$. At the $95 \%$ confidence level, the estimated error range for the ensemble mean thrust level was $\pm 0.35 \mathrm{~N}$. The mean $I_{\mathrm{sp}}$ was approximately $207.3 \mathrm{~s}$, with a burn-to-burn standard deviation of $\pm 7.25 \mathrm{~s}$. At the $95 \%$ confidence level, the estimated error range for the ensemble mean $I_{\text {sp }}$ was $\pm 2.05 \mathrm{~s}$. The mean power input for ignition was $1.53 \mathrm{~W}$ with a standard deviation of $\pm 0.39 \mathrm{~W}$. At the 
Table 2 Motor geometry parameter specifications

\begin{tabular}{|c|c|c|c|c|}
\hline \multirow{2}{*}{$\frac{\text { Parameter }}{\text { Fuel grain }}$} & \multicolumn{2}{|c|}{ Injector } & \multicolumn{2}{|c|}{ Single port, $0.127 \mathrm{~cm}(0.05 \mathrm{in}$.$) diameter$} \\
\hline & Diameter: $3.168 \mathrm{~cm}$ (1.246 in.) & Length: $6.850 \mathrm{~cm}$ & $\begin{array}{l}\text { Initial weight: High density: } \\
50.0 \mathrm{~g}\end{array}$ & $\begin{array}{l}\text { Initial port diameter: } 0.625 \mathrm{~cm} \\
\text { (0.246 in.) }\end{array}$ \\
\hline Motor case & Diameter: $3.8 \mathrm{~cm}$ (0.150 in.) & Length: $13.8 \mathrm{~cm}$ (5.43 in.) & \multicolumn{2}{|c|}{ Wall thickness: $1.5 \mathrm{~mm}(0.659 \mathrm{~mm})$} \\
\hline $\begin{array}{l}\text { High expansion ratio } \\
\text { nozzle }\end{array}$ & $\begin{array}{l}\text { Initial throat diameter: } 0.401 \mathrm{~cm} \\
\text { (0.158 in.) }\end{array}$ & $\begin{array}{l}\text { Exit diameter: } 1.215 \mathrm{~cm} \\
\text { (0.478 in.) }\end{array}$ & $\begin{array}{l}\text { Vacuum tests initial expansion } \\
\text { ratio: } 9.5: 1\end{array}$ & Nozzle exit angle: $20.0 \mathrm{deg}$. \\
\hline
\end{tabular}

Table 3 Summary of ambient and vacuum testing campaign on flight-weight small thruster

\begin{tabular}{lcclcll}
\hline \hline Case & Expansion ratio & \multicolumn{1}{c}{ Vacuum pressure } & \multicolumn{1}{c}{ Thrust } & \multicolumn{1}{c}{$I_{\mathrm{sp}}$} & Ignition power \\
\hline Ambient & $2.1: 1$ & $86 \mathrm{kPa}$ absolute (0 torr vacuum) & $\mu=22.6 \pm 0.35 \mathrm{~N}$ & $\mu=207.3 \pm 2.1 \mathrm{~s}$ & $\mu=1.53 \pm 0.11 \mathrm{~W}$ & $\mu=183 \pm 7.1 \mathrm{~ms}$ \\
& & & $\sigma= \pm 1.2 \mathrm{~N}$ & $\sigma= \pm 7.25 \mathrm{~s}$ & $\sigma= \pm 0.39 \mathrm{~W}$ & $\sigma= \pm 25.1 \mathrm{~ms}$ \\
Vacuum & $9.5: 1$ & \multirow{2}{*}{$15.2 \mathrm{kPa}$ absolute (646 torr vacuum) } & $\mu=30.85 \pm 0.88 \mathrm{~N}$ & $\mu=280.0 \pm 3.7 \mathrm{~s}$ & $\mu=1.38 \pm 0.21 \mathrm{~W}$ & $\mu=133 \pm 8.9 \mathrm{~ms}$ \\
& & & $\sigma= \pm 1.96 \mathrm{~N}$ & $\sigma= \pm 8.4 \mathrm{~s}$ & $\sigma= \pm 0.46 \mathrm{~W}$ & $\sigma= \pm 20 \mathrm{~ms}$ \\
\hline \hline
\end{tabular}

95\% confidence level, the estimated error range for the ensemble mean ignition power was $\pm 0.11 \mathrm{~W}$.

The motor ignition time $\tau_{\text {rise }}$ is calculated as the elapsed time from the opening of the run valve until the motor reaches $85 \%$ of the maximum chamber pressure. For the ambient pressure tests of the low expansion ratio nozzle, the ensemble mean rise time is $183 \mathrm{~ms}$ with a standard deviation of $\pm 25.1 \mathrm{~ms}$. At the $95 \%$ confidence level, the estimated error range for the ignition time is $\pm 7.1 \mathrm{~ms}$.

The rise time statistics presented previously only describe the fluid mechanical response of the thruster system (from the time of the run valve opening) and do not include the latency due to the spark prelead. As a matter of convenience, the pulse data presented in this paper were collected using the default $500 \mathrm{~ms}$ prelead, $500 \mathrm{~ms}$ postignition settings for the ignitor command. Qualitative studies have demonstrated that the pre- and postignition spark command settings can be considerably shortened from the default settings. Spark preleads as short as $10 \mathrm{~ms}$ have successfully initiated combustion. Unfortunately, at the time of this paper, this minimum ignition-prelead for reliable ignition has yet to be statistically quantified, and the results are not included in this paper.

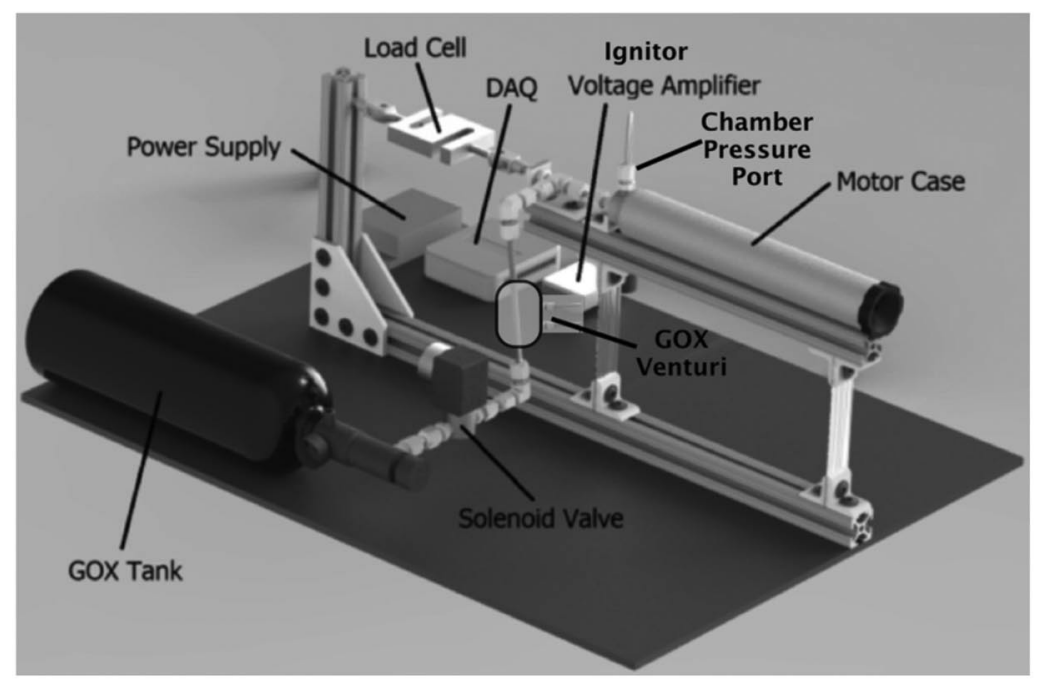

a) 3-D Schematic

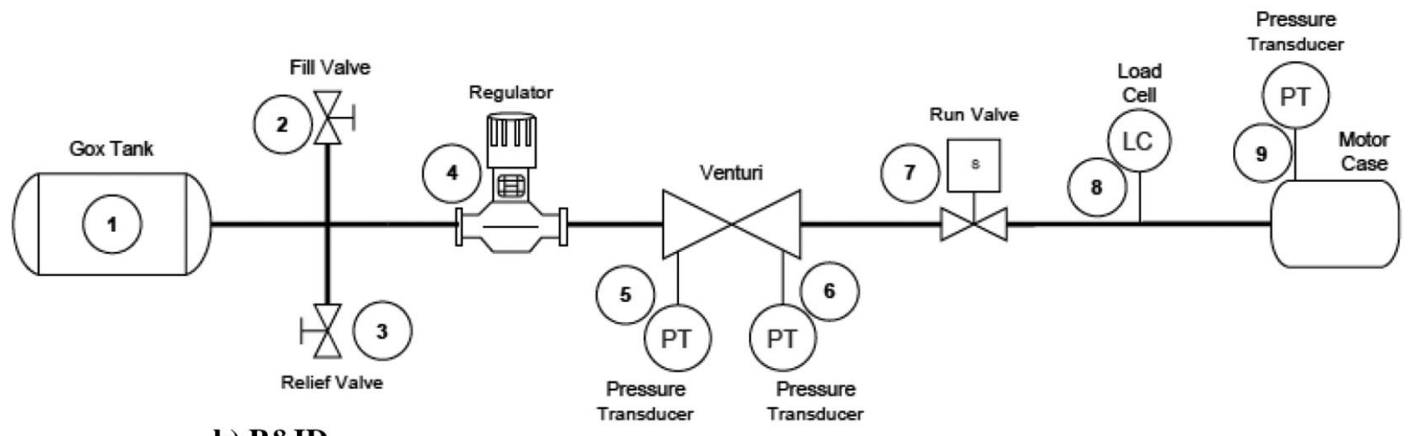

b) P\&ID

Fig. 12 Schematic of the flight-weight motor test apparatus. 


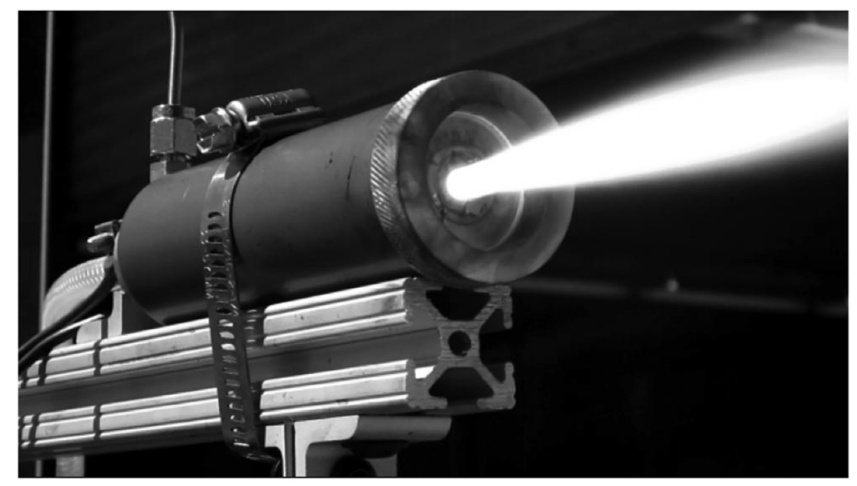

Fig. 13 Flight-weight thruster system during test firing.

\section{Vacuum Tests of the Flight-Weight System}

The flight-weight thruster system was vacuum tested during the summer of 2016 in the NASA Marshall Space Flight Center's (MSFC's) Propulsion Research and Development Laboratory. Test objectives included 1) demonstration of reliable multiple restart capability under near-vacuum conditions, 2) characterization of the vacuum specific impulse with a high expansion ratio nozzle, 3) characterization of the system startup time under vacuum conditions, and 4) identifying any possible corona discharge effects due to the high ignition voltage at low operating pressure levels. The motor and test system described in the previous section were modified to fit into the vacuum chamber. Figure 15 shows the thruster mounted on the test sled and installed in the vacuum chamber. For the vacuum tests, a separate non-flight-weight feed system delivered the oxidizer to the thrust chamber. With the thruster firing, the vacuum systems were able to maintain a mean chamber pressure of approximately $0.15 \mathrm{~atm}$. This value corresponds to a vacuum pressure of approximately 650 torr below one standard atmosphere.

Similar to the results presented by Fig. 14, the pulse burn series of the previous section was repeated as four consecutive $1 \mathrm{~s}$ burns with a $10 \mathrm{~s}$ recovery time between burns. The $10 \mathrm{~s}$ recovery time was allowed to ensure that the vacuum chamber returned to near its minimum pressure level between each burn. Figure 16 presents results from a typical test. This figure plots thrust as measured by the load cell and calculated from chamber pressure (Fig. 16b); chamber, nozzle exit, and vacuum chamber pressure (Fig. 16b); nozzle exit, oxidizer, and fuel mass flow (Fig. 16c), specific impulse as calculated from the thrust, chamber pressure, and total mass flow (Fig. 16d); ignitor input voltage (Fig. 16e), and ignitor input power and total input energy (Fig. 161).

As expected, when compared to the ambient pressure tests, the vacuum thrust and $I_{\mathrm{sp}}$ levels are noticeably higher. This increase is clearly a result of the reduced backpressure and the higher expansion ration nozzle. Interestingly, the ignitor spark voltage and power draw are more erratic for the vacuum tests with peak voltage levels jumping instantaneously to greater than $1000 \mathrm{~V}$. However, the end-to-end energy required to complete the four-burn sequence is only marginally higher when compared to the ambient-pressure tests: approximately $6.4 \mathrm{~J}$. This result indicates that the fuel material enthalpy of ablation is a primary driver in the consumed input power.

The four pulse burn tests were repeated five times, and data from a total of 20 successful $1 \mathrm{~s}$ burns were collected. The ensemble mean thrust level is $30.85 \mathrm{~N}$ with a standard deviation of $\pm 1.96 \mathrm{~N}$. At the

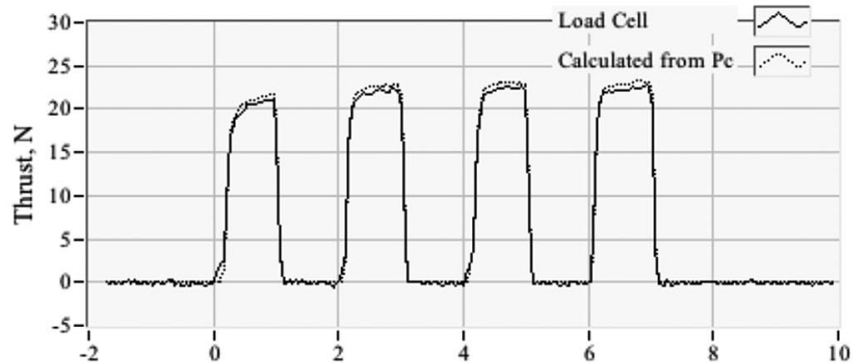

a) Thrust

Time, $s$

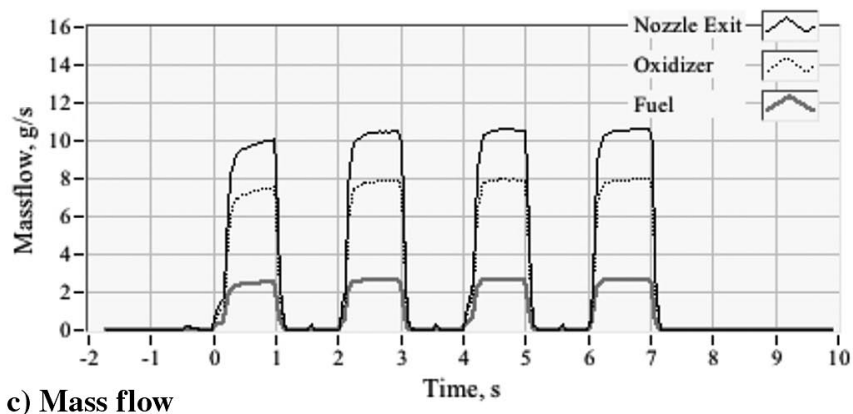

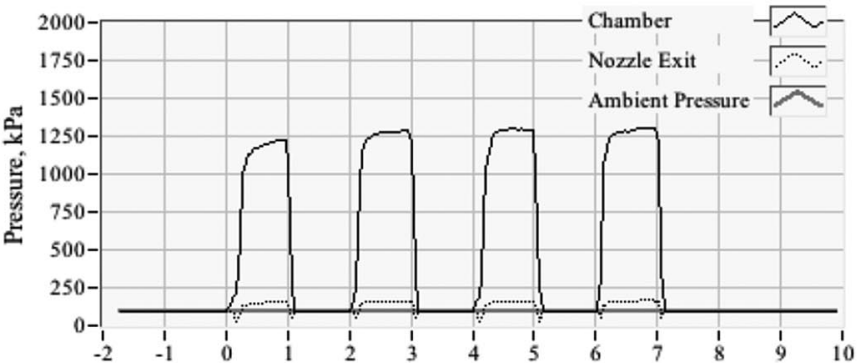

b) Pressure

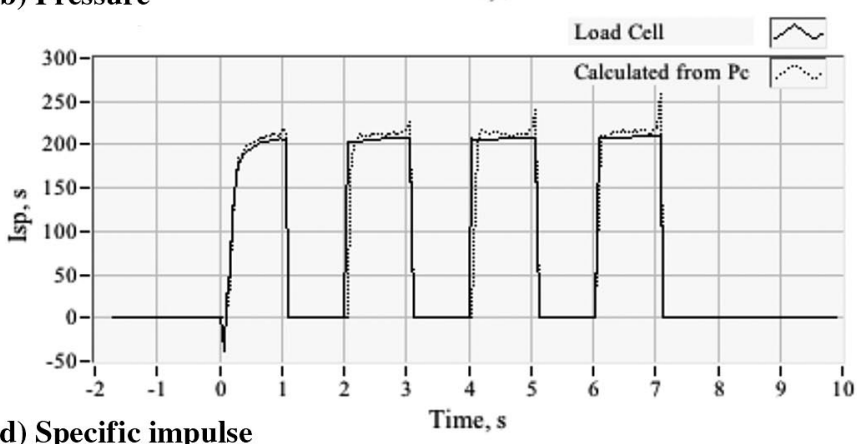

d) Specific impulse

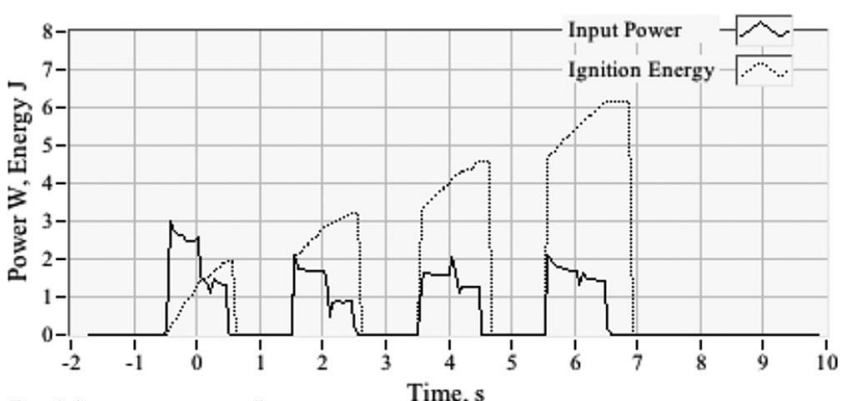

f) Ignition power and energy

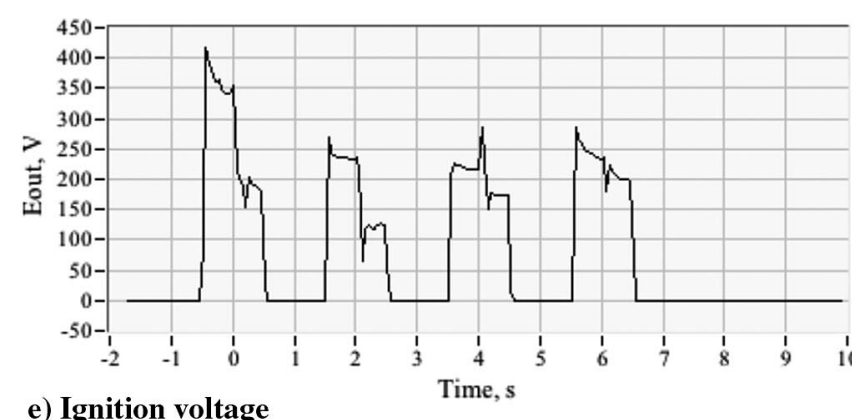

Fig. 14 Time histories of pulsed burns for ambient conditions. 

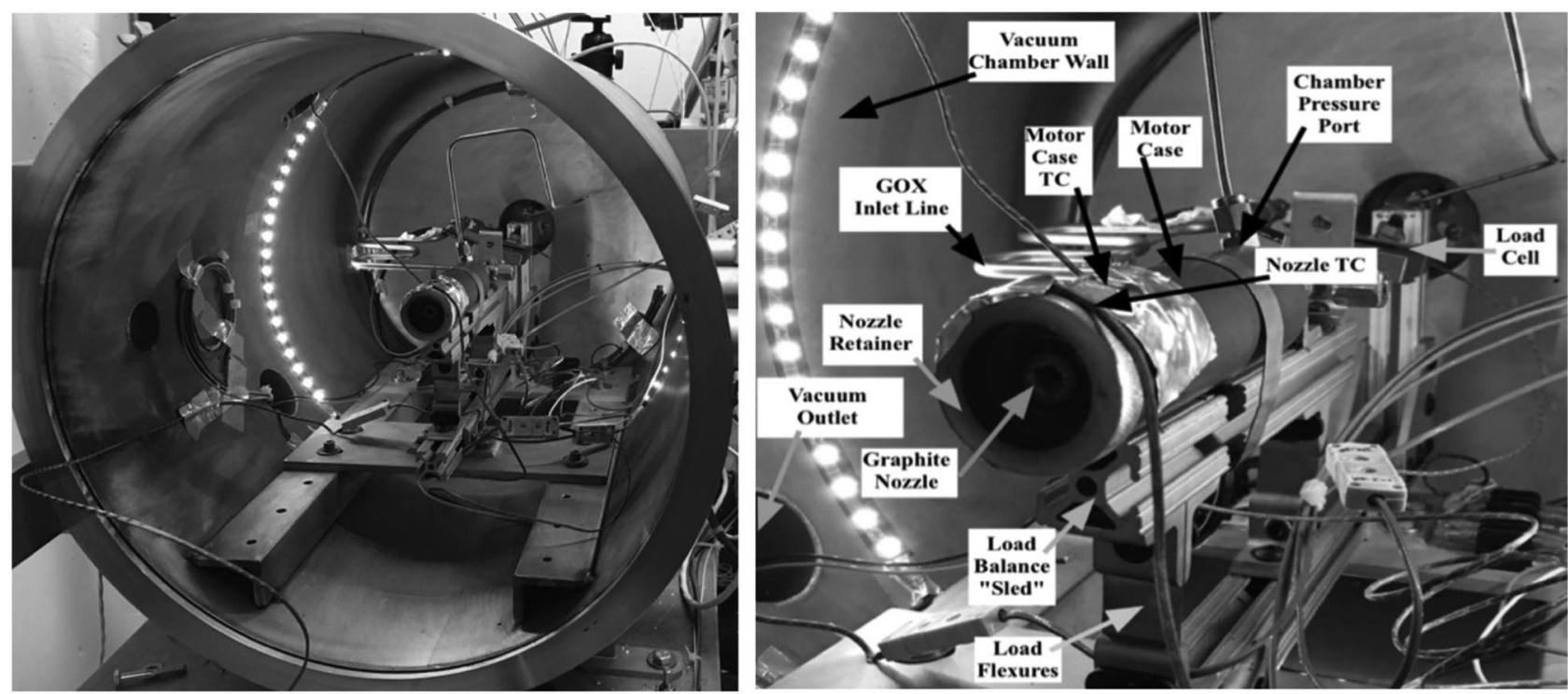

Fig. $1525 \mathrm{~N}$ thruster mounted in MSFC vacuum chamber.
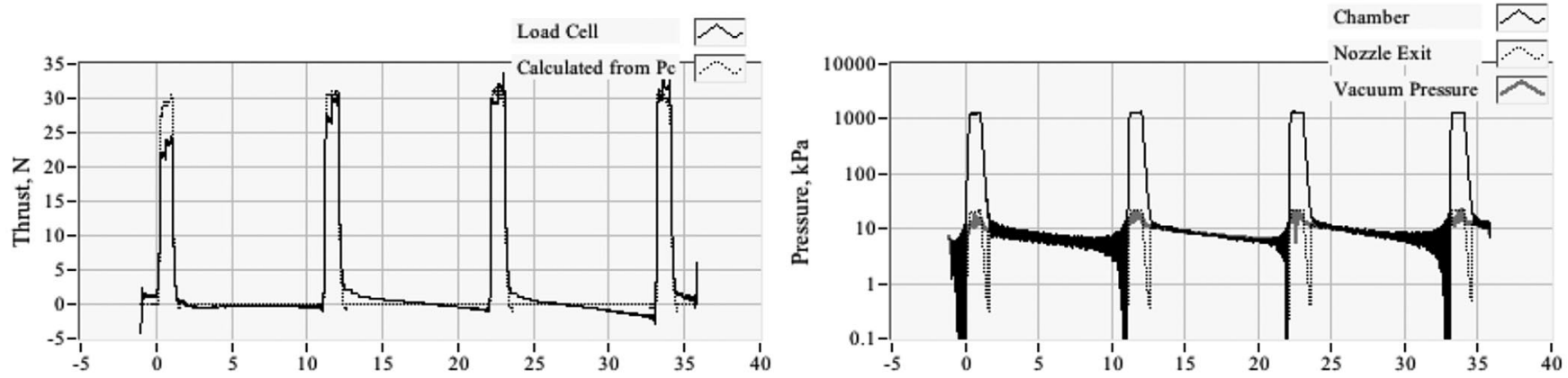

a) Thrust

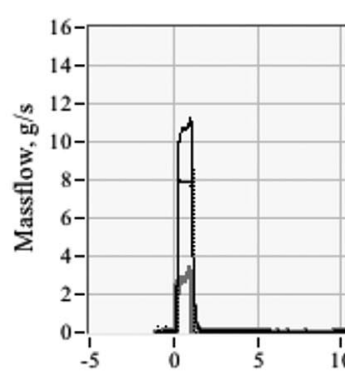

c) Mass flow

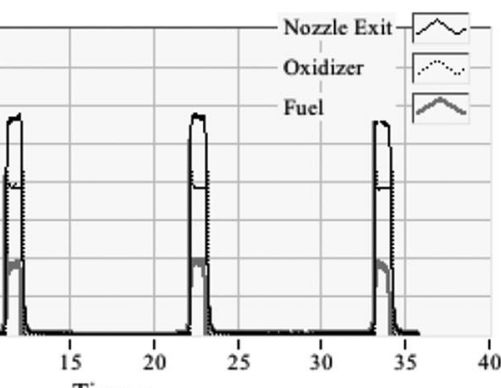

Time, $s$

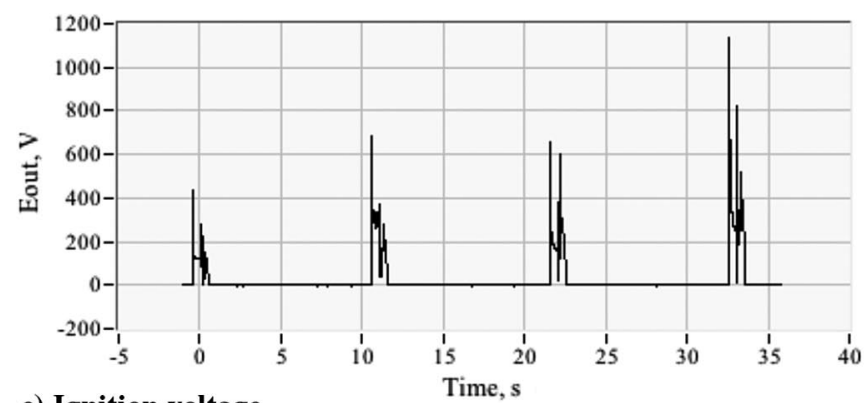

e) Ignition voltage b) Pressure

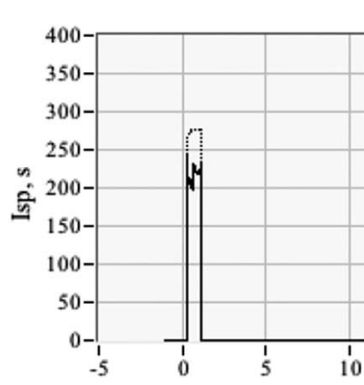

d) Specific impulse

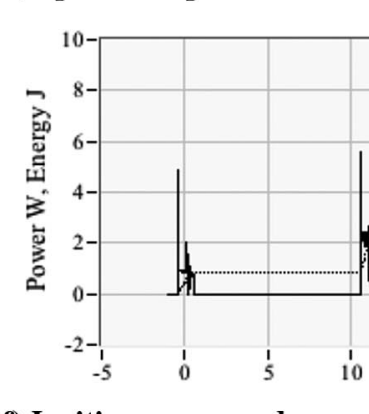

f) Ignition power and energy
Time, $\mathrm{s}$

Load Cell ,

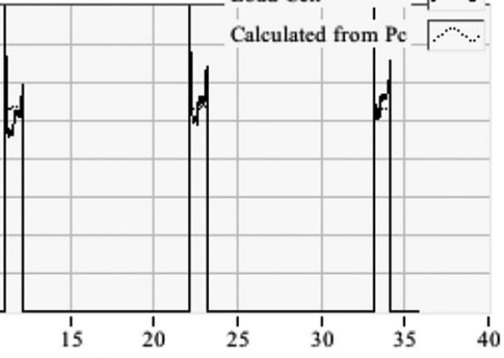

Time, $s$

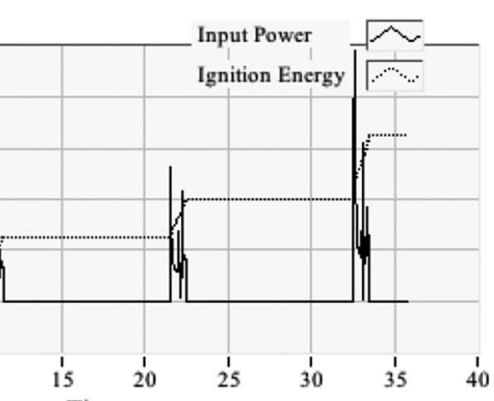

Time, $s$

Fig. 16 Time histories of pulsed burns for soft-vacuum conditions.

95\% confidence level, the estimated error range for the ensemble mean thrust is $\pm 0.88 \mathrm{~N}$. The ensemble mean $I_{\mathrm{sp}}$ is $280.0 \mathrm{~s}$ with a sample standard deviation of $\pm 8.4 \mathrm{~s}$. At the $95 \%$ confidence level, the estimated error range for the ensemble mean $I_{\mathrm{sp}}$ is $\pm 3.8 \mathrm{~s}$. The ensemble mean ignition power drawn is $1.38 \mathrm{~W}$ with a sample standard deviation of $\pm 0.46 \mathrm{~W}$. At the $95 \%$ confidence level, the estimated error in the mean ignition energy is $\pm 0.21 \mathrm{~W}$. The ensemble mean rise time for the vacuum tests is $133 \mathrm{~ms}$ with a 


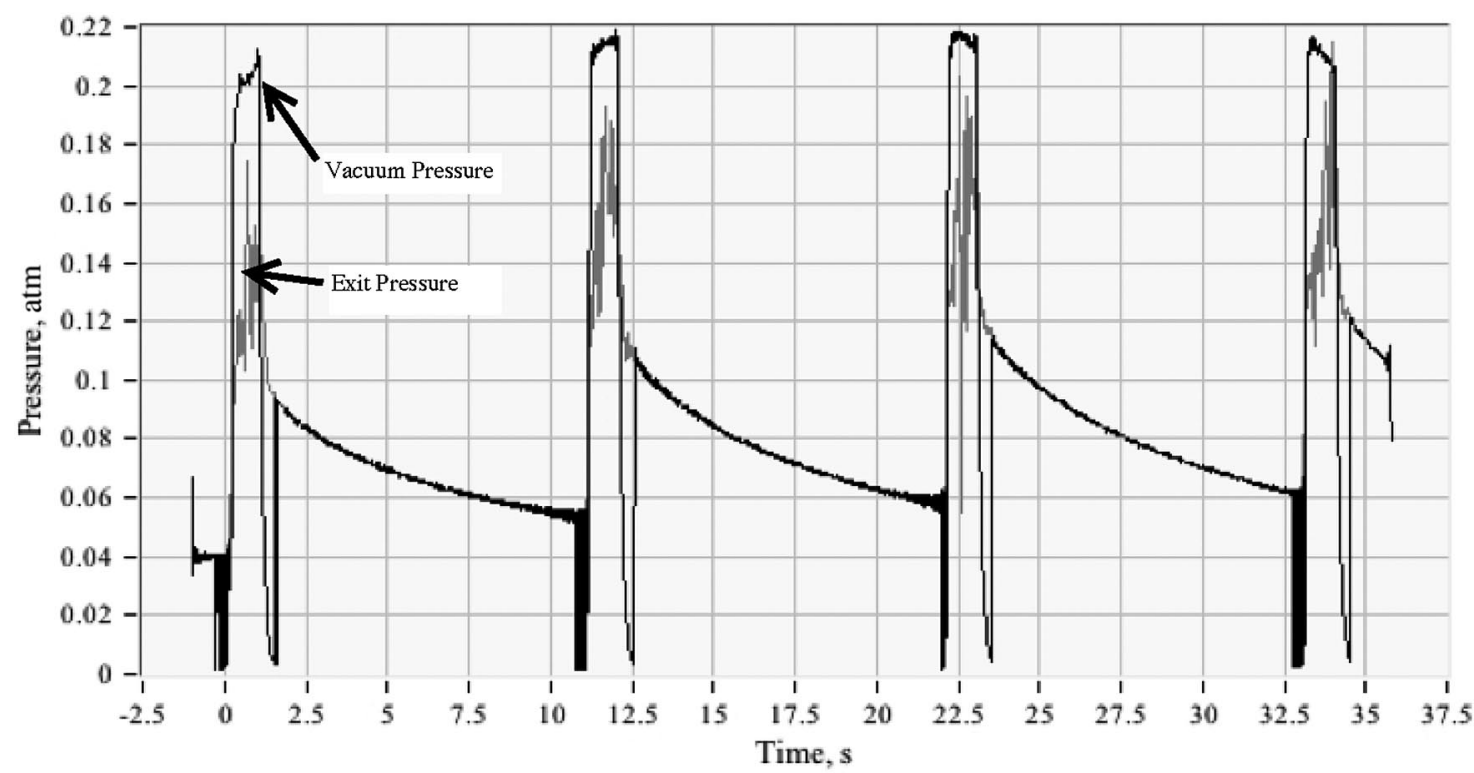

Fig. 17 Nozzle exit plane pressure compared vacuum chamber backpressure.

standard deviation of $\pm 20 \mathrm{~ms}$. At the $95 \%$ confidence level, the estimated error range for the ignition rise time is $\pm 8.9 \mathrm{~ms}$. This postGOX valve opening rise time is approximately $70 \%$ of the value measured during the ambient pressure tests. Most likely, the nozzle throat chokes sooner under vacuum conditions, thus allowing the chamber pressure to build up faster.

\section{E. Extrapolating the Specific Impulse to Hard-Vacuum Conditions}

Figure 17 compares the nozzle exit pressure to the background chamber pressure measured during a typical four-pulse vacuum test sequence. Clearly, the chamber vacuum pumping system could not hold a hard vacuum when the motor was firing, and the mean background pressure rose to approximately $15 \%$ of standard atmosphere. This pressure level corresponds to a standard altitude of approximately $13.6 \mathrm{~km}(45,000 \mathrm{ft})$.

Even though the 9.5:1 nozzle was optimized for these test conditions, the measured specific impulse of $280 \mathrm{~s}$ does not represent a true vacuum value. Using data from Table 3 , the specific impulse can be extrapolated to a hard-vacuum condition by using the onedimensional de Laval flow equations [36] to write the specific impulse in terms of the thrust coefficient and the exit pressure-tochamber pressure:

\section{Conclusions}

This paper details the developmental of an innovative green hybrid propulsion system using fused deposition modeling additive manufacturing. When fully developed, this crosscutting technology offers a wide variety of space propulsion applications, and it may allow the development of drop-in replacements for many existing hydrazinebased propulsion systems. FDM manufacturing circumvents many of the developmental issues normally associated with hybrid rocket systems. FDM manufacturing has allowed the development of multiple prototype hybrid thrusters that exhibit a high degree of restart ability, require a low-wattage input for ignition, demonstrate enhanced fuel regression rates, and offers a highly compact form factor.

After proof-of-concept tests with the ignitor and laboratory-weight motor were completed, the developed thruster technology was scaled to a flight-weight microthruster to prove the scalability of the system technology. This system was used to demonstrate multiple, successive restart capability, with precisely controlled impulse bits. When the system specific impulse obtained for a soft-vacuum condition with the 9.5:1 expansion ratio nozzle was extrapolated to hard-vacuum conditions, the result was approximately 297 s. For the 25:1 expansion ratio nozzle, the specific impulse extrapolated to 319 s. This value was $30-35 \%$ higher than could be achieved by

$$
\begin{aligned}
\frac{\left(I_{\text {sp }}\right)_{\text {vac }}}{\left(I_{\text {sp }}\right)_{\text {test }}}= & \frac{\left(\left(P_{0} \cdot A^{*}\right) /\left(g_{0} \cdot \dot{m}\right)\right)\left(C_{F_{\text {vac }}}\right)_{\mathrm{opt}}}{\left(\left(P_{0} \cdot A^{*}\right) /\left(g_{0} \cdot \dot{m}\right)\right)\left(C_{F_{\text {test }}}\right)} \\
& =\frac{\gamma \cdot \sqrt{2 /(\gamma-1)(2 /(\gamma+1))^{((\gamma+1) /(\gamma-1))} \cdot\left(1-\left(\left(p_{\text {exit }}\right)_{\text {vac }} / P_{0}\right)^{((\gamma-1) / \gamma)}\right)}+\left(A_{\text {exit }} / A^{*}\right)_{\text {vac }} \cdot\left(\left(p_{\text {exit }}\right)_{\text {vac }} / P_{0}\right)}{\gamma \cdot \sqrt{2 /(\gamma-1)(2 /(\gamma+1))^{((\gamma+1) /(\gamma-1))} \cdot\left(1-\left(\left(p_{\text {exit }}\right)_{\text {test }} / P_{0}\right)^{((\gamma-1) / \gamma)}\right)}+\left(A_{\text {exit }} / A^{*}\right)_{\text {test }} \cdot\left(\left(\left(p_{\text {exit }}\right)_{\text {test }}-p_{\infty}\right) / P_{0}\right)}
\end{aligned}
$$

Assuming a mean chamber pressure level of $195 \mathrm{psia}(1250 \mathrm{kPa})$, a test vacuum pressure of $15 \mathrm{kPa}$, and a ratio of specific heats of 1.18 , the thruster with the 9.4 expansion ratio nozzle extrapolates to give a hard-vacuum specific impulse of $296.5 \mathrm{~s}$. When the nozzle is more optimized for vacuum operating conditions (e.g., $\left.A_{\text {exit }} / A^{*}=25: 1\right)$, then the exit pressure drops to $6.7 \mathrm{kPa}$ and the specific impulse extrapolates to $319 \mathrm{~s}$. This value is $30-35 \%$ greater than can be achieved by monopropellant hydrazine [2] or either of the ionic liquid green propellants (LMP-103s [6] or AFM315E [9]). monopropellant hydrazine or either of the ionic liquid green propellants (LMP-103s or AF-M315E).

The development and testing of this flight-weight system, along with the results from early development testing, prove the ability of an additively manufactured grain to be used as a drop-in replacement for hydrazine-based systems for smallsat systems. The presented system maintains a consistent restart capability and compact form factor of a hydrazine system while improving significantly on the safety, environmental sustainability, performance, power consumption, and cost of materials and operation. 


\section{References}

[1] Bombelli, V., "Economic Benefits for the Use of Non-Toxic Monopropellants for Spacecraft Applications," 39th AIAA/ASME/ SAE/ASEE Joint Propulsion Conference and Exhibit, AIAA Paper 2003-4783, July 2003.

[2] Haeseler, D., Bombelli, V., Vuillermoz, P., Lo, R., Marée, T., and Caramelli, F., "Green Propellant Propulsion Concepts for Space Transportation and Technology Development Needs," Proceedings of the 2nd International Conference on Green Propellants for Space Propulsion, ESA, SP-557, Cagliari, Sardinia, Italy, June 2004.

[3] Goldstein, E., "The Greening of Satellite Propulsion," Aerospace America, Feb. 2012, pp. 26-28.

[4] Pokrupa, N., Anglo, K., and Svensson, O., "Spacecraft System Level Design with Regards to Incorporation of a New Green Propulsion System," 46th AIAA/ASME/SAE/ASEE Joint Propulsion Conference and Exhibit, AIAA Paper 2011-6129, July-Aug. 2011.

[5] Nagamachi, M. Y., Oliveira, J. I., Kawamoto, A. M., and Dutra, R. C., "AND—The New Oxidizer Around the Corner for an Environmentally Friendly Smokeless Propellant," Journal of Aerospace Technology Management, Vol. 1, No. 2, Dec. 2009, pp. 153-160. doi:105028/jatm/2009.0102153160

[6] Persson, M., Anflo, K., and Dinardi, A., "A Family of Thrusters for ADN-Based Monopropellant LMP-103S," 48th AIAA/ASME/SAE/ ASEE Joint Propulsion Conference and Exhibit, AIAA Paper 20123815, July-Aug. 2012.

[7] Meinhart, D., "Selection of Alternate Fuels for HAN-BASED Monopropellants," 27th JANAFF PDCS and 16th SandEPS Joint Meeting, CPIA Pibl. 674, Vol. 1, April 1998, pp. 143-147.

[8] Hawkins, T. W., Brand, A. J., McKay, M. B., and Tinnirello, M., "Reduced Toxicity, High Performance Monopropellant at the U.S. Air Force Research Laboratory," 4th International Association for the Advancement of Space Safety Conference, AFRL-RZ-ED-TP-2010219, May 2010.

[9] Anflo, K., and Crowe, B., "In-Space Demonstration of an ADN-based Propulsion System," 47th AIAA/ASME/SAE/ASEE Joint Propulsion Conference and Exhibit, AIAA Paper 2011-5832, July-Aug. 2011.

[10] Spores, R. A., Masse, R., and Kimbrel, S., "GPIM AF-M315E Propulsion System," 49th AIAA/ASME/SAE/ASEE Joint Propulsion Conference and Exhibit, AIAA Paper 2013-3849, July 2013.

[11] Katsumi, T., and Hori, K., "Combustion Wave Structure of Hydroxylammonium Nitrate Aqueous Solutions," 46th AIAA/ASME/ SAE/ASEE Joint Propulsion Conference and Exhibit, AIAA Paper 2010-6900, July 2010.

[12] Whitmore, S. A., and Burnside, C. G., "Performance Analysis of a High Performance Green Propellant Thruster," Proceedings of the NASA Marshall Space Flight Center Faculty Program, NASA TM-2015218216, Dec. 2015, pp. 125-151.

[13] Anon., "Hazard Analysis of Commercial Space Transportation; Vol. 1, : Operations, Vol. 2: Hazards, Vol. 3: Risk Analysis," U.S. Dept. of Transportation, Document PB93-199040, Accession No. 00620693, May 1988.

[14] Chiaverini, M. J., Serin, N., Johnson, D. K., Lu, Y-C., Kuo, K. K., and Risha, G. A., "Regression Rate Behavior of Hybrid Rocket Solid Fuels," Journal of Propulsion and Power, Vol. 16, No. 1, Jan. 2000, pp. 125-132. doi:10.2514/2.5541

[15] Anon., "Eletromagnetic Environmental Effects requirements for Systems," U.S. Dept. of Defense Interface Standard MIL-STD-464, XXXX, http://www/tscm/com/MIL-STD-464/pd] [retrieved 8 Oct. 2012].

[16] Anon., "Workpace Safety and Health Topics: Isocyanates," Centers for Disease Control and Prevention, Atlanta, GA, http://www/cdd.gov, niosh/topics/isocyanates [retrieved 25 Feb. 2013].

[17] Anon., "Weapons Systems and Platforms (WP) Focus Area. Environmentally Friendly Sustainable Binder System for Energetic Materials," Strategic Environmental Research and Development Program, Exploratory Development (SEED) BAA-13-0002, FY2014 SEED Statement of Need, WPSEED-14-01, 2014.

[18] Foust, J., "SapceShipTwo Bounces Back to Rubber Fuel," SpaceNews, 14 Oct. 2015, http://spacenews;com/virgin-galactic-switching-back-torubber-fuel-for-spaceshiptwo/ [retrieved 1 Aug. 2016].

[19] Rifkin, J., The Third Industrial Revolution, How Lateral Power is Transforming Energy, the Economy, and the World, St. Martens Press, New York, 2011

[20] Whitmore, S. A., Peterson, Z. W., and Eilers, S. D., "Comparing Hydroxyl Terminated Polybutadiene and Acrylonitrile Butadiene Styrene as Hybrid Rocket Fuels," Journal of Propulsion and Power, Vol. 29, No. 3, May-June 2013, pp. 582-592. doi:10.2514/11.B34382
[21] Harper, C.A., Handbook of Plastics and Elastomers, McGraw-Hill, New York, 1975, pp. 1-3, 1-62, 2-42, 3-1.

[22] Shugg, W. T., Handbook of Electrical and Insulating Materials, Van Nostrand Reinhold, New York, 1986.

[23] Whitmore, S. A., Inkley, N. R., and Merkley, D. P., "Development of a Power Efficient, Restart-Capable Arc Ignitor for Hybrid Rockets," 50th AIAA/ASME/SAE/ASEE Joint Propulsion Conference and Exhibit, AIAA Paper 2014-3949, July 2014.

[24] Whitmore, S. A., Inkley, N. R., Merkley, D. P., and Judson, M. I., "Development of a Power-Efficient, Restart-Capable Arc Ignitor for Hybrid Rockets," Journal of Propulsion and Power, Vol. 31, No. 6, 2015, pp. 1739-1749. doi:10.2514/1.B35595

[25] Whitmore, S. A., Spurrier, Z. S., Fuller, J. K., and Desain, J. D., "A Survey of Additively Manufactured Propellant Materials for Arc-Ignition of Hybrid Rockets," 51st AIAA/SAE/ASEE Joint Propulsion Conference, Propulsion and Energy Forum, AIAA Paper 2015-4034, July 2015

[26] Whitmore, S. A., Merkley, S. L., Tonc, L., and Mathias, S. D., "Survey of Selected Additively Manufactured Propellants for Arc Ignition of Hybrid Rockets," Journal of Propulsion and Power, Vol. 32, No. 6, 2016, pp. 1494-1504.

doi:10.2514/11B36106

[27] Bath, A., "Performance Characterization of Complex Fuel Port Geometries for Hybrid Rocket Fuel Grains," M.S. Thesis, College of Engineering and Applied Sciences, Utah State Univ., Logon, UT, Dec. 2012.

[28] Fuller, J. K., Ehrlich, D. A., Lu, P. C., Jansen, R. P., and Hoffman, J. D., "Advantages of Rapid Prototyping for Hybrid Rocket Motor Fuel Grain Fabrication," 47th AIAA/ASME/SAE/ASEE Joint Propulsion Conference and Exhibit, AIAA Paper 2011-5909, July-Aug. 2011.

[29] Arnold, D., Boyer, J. E., Kuo, K. K., DeSain, J. D., Curtiss, T. J., and Fuler, J. K., "Test of Hybrid Rocket Fuel Grains with Swirl Patterns Fabricated Using Rapid Prototyping Technology," 49th AIAA/ASME/SAE/ASEE Joint Propulsion Conference, AIAA Paper 2013-4141, July 2013.

[30] Cheng, C. G., Farmer, R. C., Jones, H. S., and McFarlane, J. S., "Numerical Simulation of the Internal Ballistics of a Hybrid Rocket," 30th AIAA/ASME/SAE/ASEE Joint Propulsion Conference and Exhibit, AIAA Paper 1994-0554, July 1994.

[31] Whitmore, S. A., "Additively Manufactured Acrylonitrile-ButadieneStyrene-Nitrous-Oxide Hybrid Rocket Motor with Electrostatic Igniter," Journal of Propulsion and Power, Vol. 31, No. 4, 2015, pp. 1217-1220. doi:10.2514/1/B35681

[32] Persson, M., Anflo, K., and Dinardi, A., "A Family of Thrusters for ADN-Based Monopropellant LMP-103S," 48th AIAA/ASME/SAE/ ASEE Joint Propulsion Conference and Exhibit, AIAA Paper 20123815, July-Aug. 2012.

[33] Whitmore, S. A., Walker, S. D., Merkley, D. P., and Mansour Sobbi, M., "High Regression Rate Hybrid Rocket Fuel Grains with Helical Port Structures," Journal of Propulsion and Power, Vol. 31, No. 6, 2015, pp. $1727-1738$.

[34] Whitmore, S. A., Walker, S. D., and Merkley, D. P., "Engineering Model for Hybrid Rocket Regression Rate Amplification by Helical Fuel Ports," 51st AIAA/SAE/ASEE Joint Propulsion Conference, Propulsion and Energy Forum, AIAA Paper 2015-3745, July 2015.

[35] Whitmore, S. A., and Walker, S. D., "Engineering Model for Hybrid Fuel Regression Rate Amplification Using Helical Ports," Journal of Propulsion and Power, Vol. 32, No. 6, 2016, pp. 1674-1694. doi: $[10.2514 / 1$. B36208

[36] Anderson, J. D., Jr., Modern Compressible Flow with Historical Perspective, 3rd ed., McGraw-Hill, New York, 2003, pp. 127-187.

[37] Gordon, S., and McBride, B. J., "Computer Program for Calculation of Complex Chemical Equilibrium Compositions and Applications," NASA RP-1311, 1994.

[38] Kuo, K. K., and Chiaverini, M. J., Fundamentals of Hybrid Rocket Combustion and Propulsion, Progress in Astronautics and Aeronautics, AIAA, Reston, VA, 2007, Chap. 7.

[39] Whitmore, S. A., and Merkley, S. L., "Effects of Radiation Heating on Additively Printed Hybrid Fuel Grain O/F Shift," 52nd AIAA/SAE/ASEE Joint Propulsion Conference, Propulsion and Energy Forum, AIAA Paper 2016-4867, July 2016.

[40] Whitmore, S. A., and Mathias, S., "Development and Testing of Three Alternative Designs for Additively Manufactured Hybrid Thrusters," 52nd AIAA/SAE/ASEE Joint Propulsion Conference, Propulsion and Energy Forum, AIAA Paper 2016-4867, July 2016.

E. G. Lightsey Associate Editor 


\section{Queries}

1. AU: Please check that the copyright (@) type is correct. Please note that the code will be added upon publication.

2. AU: Please note that, if quotation marks are used to set off an unusual term in the text, AIAA requires them to be deleted from subsequent usage of the same term.

3. AU: Definitions of acronyms and abbreviations were moved from the abstract into the text of the article, per AIAA style.

4. AU: Please note that AIAA requires acronyms be used more than once to remain in the paper.

5. AU: Please review and edit the sentence beginning "With these thermosetting materials scrap..." for clarity.

6. AU: The footnote containing the url http://3dprint.com/95914/nasa-3d-print-f1-rocket-engine/ appears to take the reader to a published article. If this is the case, please change to a reference, citing it in numerical order and renumbering other references and citations as needed. If not, please provide a valid url. Lastly, please note that a date of retrieval is required for all urls.

7. AU: The url https://en.wikipedia.org/wiki/Fused_deposition_modeling/was removed, as it is not valid. Please provide a valid url and date of retrieval. Also, as AIAA does not consider Wikipedia as a reliable source, please provide a url that is not associated with Wikipedia.

8. AU: AIAA has indicated online color for the figures; however, no color was shown in any of the figures provided. Please verify the usage of color in your proof is correct.

9. AU: The footnote lists an article titled Dimension 1200es, Durability Meets Affordability, which appears to qualify as a reference; however, the url goes to a 3D printers page for Stratasys. If citing a reference, please add to the reference list; if noting a Web page, please clarify. If necessary, please do both.

10. AU: Please define TTL.

11. AU: "Figure 1." was deleted from the beginning of Fig. 7's caption for clarity. If it has significance, please clarify.

12. AU: Parentheses were removed from around the grain numbers so that they would not be confused with equation citations. Please confirm your meaning was retained.

13. AU: Please define AN, DAQ, and TC in the figures.

14. AU: Please review and edit the sentence beginning "FDM manufacturing has allowed the..." for clarity.

15. AU: For Ref. [7], please provide the full name and location of the publisher (NOT the conference host).

16. AU: If Ref. [8] is a published proceedings, please provide the full name and location of the publisher (NOT of the conference host) and the page range. If it is a conference paper, please provide the paper number and the organizer's name.

17. AU: Please provide the dates of publication for Refs. [15, 16].

18. AU: For Ref. [17], please provide the location of the institution.

19. AU: Please provide the pages used for Refs. [19, 22]. 